\title{
Acquisition of Grammatical Gender in Italian as a Foreign Language
}

\author{
Katrina Oliphant \\ University of Hawai' $i$
}

\begin{abstract}
This study investigated the sensitivity to gender cues exhibited by L2 learners of Italian. The participants were 64 students in first- and second-year Italian classes at the university level. Three tests were given to ascertain the students' ability to assign gender based on morphophonological, syntactic, and semantic cues. Results showed that the students were sensitive to cues in the wordfinal phonemes that reliably indicate gender and implicational scaling demonstrated a clear order of difficulty among these endings. The students exhibited a low degree of awareness of the gender associations of certain derivational suffixes. When dealing with more than one cue, the students had no difficulty assigning gender when the cues were in accord, while coping with conflicting cues was more problematic, particularly when there was discord with natural gender. Nonetheless, in the majority of the cases, the students were able to use syntactic cues to override competing cues. While as a group, the students were reliant on a syntactic strategy, the implication scaling performed on the results revealed the presence of subgroups following different strategies, i.e., morphophonological or semantic. Clear scales of difficulty among the various combinations of cue types also emerged.
\end{abstract}

\section{Literature review}

In languages where it exists, the system of grammatical gender is mastered by native speakers at an early age without the need for explicit rules. However, gender appears to be a difficult obstacle to surmount in an L2 for learners with an English language background (Andersen, 1984; Carroll, 1989; Delisle, 1985; Harley, 1979, in press; Rogers, 1987; Stevens, 1984; Surridge, 1993; Surridge \& Lessard, 1984; Tucker, Lambert, \& Rigault, 1969, 1977). Research has shown that L1 speakers do not depend on rote memorization in order to correctly assign gender to nouns; rather they have developed a sensitivity to competing cues that facilitate their choices (Berman, 1986; Cain, Weber-Olsen, \& Smith, 1987; Clark, 1986; Karmiloff-Smith, 1979; Levy, 1983; Mills, 1986; Pérez-Pereira, 1991; Surridge, 1993).

\section{L1 research}

One of the first studies which looked at L1 speakers' skill with this aspect of their language was carried out by Tucker, et al. (1977). The motivation for this research grew out of Tucker's curiosity about the difficulties he experienced with gender distinctions as an L2 learner of French. Dissatisfied with previous research on gender, which was based on limited noun samples and provided only incomplete or incorrect generalizations about the relationship between noun endings and gender, Tucker, et al. analyzed the entire noun corpus of the 1962 edition of the Petit Larousse dictionary. They found that, rather than being unreliable predictors of gender, as was previously believed, noun endings "co-occur in a systematic and predictable manner" with gender (Tucker, et al., 1977, p. 57). Further research showed that the native French speakers in this study (ages 7-17) reproduced these distributional regularities in their assignment of gender to rare and nonce nouns, suggesting that noun endings play an important role in gender assignment. Determining gender in French appears to be an active process, in which native speakers "focus on the ending as the most probable gender marker, and then scan backwards into the words until they can determine in which particular subcontext the terminal phone occurs" (Tucker, et al., 1977, p. 62). Thus when faced with a word like maison, a French speaker can focus beyond the final -on (masculine in the word son) to the feminine ending -aison and then correctly assign it to the feminine. In situations where the noun ending was rare with a salient counterexample to the usually co-occurring 
gender, the subjects tended to choose the gender of the commonly-used exception, suggesting that "the speakers' skill with grammatical gender is tied to the amount of language experience available" (Tucker, et al., 1977, p. 58). Results suggest that the beginnings of words might also have played a role in the subjects' choices in cases where the endings were ambiguous as to gender. The spelling of the nouns also provided cues to gender, as in the case of the endings -eur (masculine) and -eure (feminine), indistinguishable by pronunciation alone.

Although they appeared to have implicit knowledge of the cues in endings, the participants in the Tucker, et al. study tended to be "insensitive to their dependence on regularities in the language," responding when questioned about word endings that they were not reliable predictors of gender (Tucker, et al., 1977, p. 46). When asked about the strategies they used in assigning gender to a new word, many participants reported trying the noun out with the masculine and feminine indefinite articles to see which sounded better. Some of the children also mentioned thinking of other words that sounded like the noun in question in order to decide on its gender.

While the Tucker, et al. study was of substantial import for having shown that, rather than being arbitrary, gender assignment is related to morphophonological markers, it did not look at how native speakers behave when confronted with other cues to gender, i.e., semantic (natural gender) and syntactic (agreement) cues. This issue was taken up by Karmiloff-Smith (1979) in her study of French-speaking children's use of determiners. She investigated the hypothesis that children come to awareness of intralinguistic cues to gender, i.e., phonological/morphological and syntactic cues, later in their development, while their initial point of reference is extralinguistic, i.e., natural gender differences. She presented her subjects (ages 3-12) with pictures of imaginary animate and inanimate objects, to which she gave French-sounding names. She then elicited statements about the pictures in order to ascertain the subjects' sensitivity to various combinations of the three types of gender cues. Contrary to the aforementioned hypothesis, she found that semantic cues had less effect on the children's assignment of gender to these objects than did phonological and syntactic cues. Children up until around the age of nine used a predominately phonological strategy, though as early as age three they showed sensitivity to syntactic and semantic cues when they did not conflict with word endings. The fact that discord among cues created more difficulty than no discord also suggests that, to some extent, children in all age groups were able to take into account all three types of cues. The awareness of the greater reliability of syntactic cues appeared to increase with age, as did a sensitivity to semantic cues. There was a tendency, particularly among the older children, to attribute nouns more often to the masculine.

Pérez-Pereira (1991), using a procedure similar to that employed by Karmiloff-Smith (1979), showed that the Spanish children (ages 4-11) in his study were more sensitive to intralinguistic than to extralinguistic cues as well. Natural gender did play a role though in cases where the morphophonological and syntactic cues were in conflict. The results showed that "the agreement of the natural gender clue with another clue increase[d] the probability of gender being determined as a response against the contrary clue" (Pérez-Pereira, 1991, p. 583). Though the overall results in situations of discord between article and noun-ending were similar to those found by Karmiloff-Smith, there did not seem to be a clear developmental trend towards focus on the syntactic cue in the Spanish children as there was for the French. The Spanish children at age four were already somewhat aware of the greater importance of syntactic cues. When they were not in conflict, morphophonological cues appear to be weighted more strongly than syntactic cues, as in the French study. Performance improved with the number of complementary cues, demonstrating "that children can take into account and process several clues at the same time" (Pérez-Pereira, 1991, p. 584). The Spanish children's tendency to attribute nouns to the masculine was even greater than that of the French-speaking children in Karmiloff-Smith's study. 
Mills (1986), in her analysis of the spontaneous use of gender by three young German children, ascertained the primacy of intralinguistic cues in these participants' acquisition of the grammatical gender system. Though they were aware of natural gender distinctions, they did not assign gender based on semantic cues when there was conflict with morphological or syntactic cues. Here the feminine appeared to function as the default gender, as these children tended to overgeneralize the feminine articles.

In her study of the acquisition of Hebrew plurals, Levy (1983) found that Israeli children at ages 2-3 used neither a semantic nor a syntactic strategy in their prediction of the plural form of nouns. Rather, they were reliant on cues in the endings of the singular nouns. These findings are confirmed by Berman (1986) in his study of Hebrew L1 acquisition. Levy (1988) believes that children's initial conception of gender as a formal rather than semantic feature of language can be explained by the fact that, in languages where gender regularities are transparent, the gender system is in large part acquired before natural gender becomes a linguistically salient aspect of the language. Both the Levy (1983) and Berman (1986) studies found that Israeli children manifested a preference for masculine articles.

The spontaneous production of two French-German bilingual children (ages 1-5) analyzed in studies by both Koehn (1994) and Müller (1994) also demonstrated a phonological approach to gender. Natural gender did not play a significant role, evidenced by the mismatch between the article and the semantic gender of the referent in expressions such as *le dame, *le maman, and *die Papa (Müller, 1994).

The L1 research makes clear that young children learning their first language do not use a semantic strategy in acquiring grammatical gender, while the relative weight they give to morphophonological and syntactic cues varies from study to study, seemingly a function of age level. It is apparent that children develop an increasing ability to process and integrate competing cues which allows them to cope with the complexities of gender agreement.

\section{L2 research}

This capacity to deal successfully with grammatical gender tends to elude English-speaking L2 learners, who come from a language background which limits the grammatical marking of gender to changes in pronouns based on sexual dimorphism. A number of studies have been undertaken to examine this issue. The research that has been carried out in this area has tended to concentrate on comparing the type of cue sensitivity exhibited by L2 learners (in metalinguistic judgments or in elicited speech) to that of native speakers or other $\mathrm{L} 2$ learners with different language backgrounds (Cain, et al., 1987; Delisle, 1985; Hardison, 1992; Marinova-Todd, 1994, as cited in Bialystok, 1997; Stevens, 1984; Surridge \& Lessard, 1984; Zekhnini \& Hulstijn, 1995) or to analyzing L2 learners' speech or written production errors of gender agreement (Andersen, 1984; Finneman, 1992; Harley, 1979; Rogers, 1987). A few studies have also investigated teaching practices directed at improving L2 learners' performance with grammatical gender (Desrochers, Gélinas, \& Wieland, 1989: Harley, in press; Luce, 1979; Tucker, et al., 1969). Others have probed L1 speakers' reactions to gender errors in the production of second language learners (Lepicq, 1980, cited in Harley, in press; Magnan, 1983).

Surridge and Lessard (1984) tested Canadian university students, most in their fourth year of French as a second language, to ascertain their sensitivity to gender cues in word endings. The students were given a list of sixty nouns, with which they were expected to be familiar, and then asked to mark them as masculine or feminine. The researchers found that French L2 learners, like French native speakers, are sensitive to phonological cues to gender. The students did best at assigning gender to high frequency nouns, followed by less frequent nouns with endings found by Tucker, et al. (1977) to be highly 
predictable for gender, with a marked decrease in accuracy for infrequent nouns with the gender opposite to that usually associated with their endings or with endings that are ambiguous as to gender.

Hardison (1992) carried out a similar series of studies in which she hoped to learn not only about L2 learners' competence in assigning gender in French based on word endings, but also about the strategies that guided their choices. She, too, found that her American university student subjects were able to make use of cues in word endings. In retrospective interviews, her subjects "reported focusing their attention on noun endings for both their sound and spelling cues in gender assignment" (Hardison, 1992, p. 301). They also revealed using strategies akin to those of the French L1 speakers in the Tucker, et al. (1977) study. They "utilize[d] sound similarities between known words and unfamiliar ones to assign gender," a strategy that proved problematic when a salient member of a noun ending category was an exception to the general tendency (Hardison, 1992, p. 301). When trying to recall the gender of a known word, the subjects reported trying to recall it in gender-marked contexts, suggesting the importance of syntactic cues. This strategy, according to Tucker, et al. (1977) is also used by native French speakers. Also like L1 speakers, L2 students stated that at times they chose the article that sounded the best.

Zekhnini \& Hulstijn (1995) investigated the claim made by Carroll (1989) that the differences between L1 and L2 speakers' ability to assign gender lies in the encoding process. While native speakers encode gender as an intrinsic feature of the noun, non-native speakers of languages without gender "transfer their noun category - crucially without an inherent gender feature to the tasks of acquiring new words" (Carroll, 1989, p. 581). In a series of experiments, Zekhnini \& Hulstijn taught nonce Dutch nouns, both with and without morphophonological cues to gender, along with their articles, to adult L1 and L2 speakers of Dutch, who were later required to reproduce the nouns with the proper articles when shown a picture of the noun referent. The researchers found that both groups had difficulty remembering the gender of new nouns which possessed no cue to gender. Differences between the two groups in terms of mean number and distribution of errors was non-significant. On the other hand, while native speakers had little difficulty with nouns whose endings gave clear cues to their gender, the non-native speakers made a notable number of errors with these items, though, as in the Surridge and Lessard (1984) and Hardison (1992) studies, the number of mistakes was significantly lower than with nouns with no cues to gender, suggesting that the L2 speakers possessed a sensitivity to morphophonological cues. In the opinion of Zekhnini \& Hulstijn, these findings demonstrate that native speakers do not "automatically and without failure encode the gender feature upon the first few encounters with new nouns" (1995, p. 135). They acknowledge that their results conflict with the L1 acquisition research which has found that young children have little difficulty assigning gender. The discord, they believe, may lie in the L1 studies themselves, which have not examined first-time article use with newly learned nouns, or in the possibility that children possess greater mnemonic abilities than do adults. The superiority of Dutch L1 speakers to L2 learners in assigning gender to nouns with clear cues to gender is not caused by differences in modes of cognitive processing, say Zekhnini \& Hulstijn, but rather by the fact that native speakers have had greater experience with the language and are thus more attuned to gender cues.

While the three aforementioned studies focused only on sensitivity to the cues in noun endings, Stevens (1984) looked at how English-speaking children in a Montreal French immersion program dealt with phonological, syntactic, and semantic cues to gender, through replication of three of KarmiloffSmith's (1979) gender tasks. Rather than elicit metalinguistic judgments as in the aforementioned research on French L2 learners, this study required the subjects to produce statements demonstrating ability to make gender agreement. The children varied in age (6-13 years) and in number of years of French study (1-6 years). Stevens found that these children were similar in a number of ways to the native French speakers in Karmiloff-Smith's study. Children of all ages made use of phonological cues in noun endings 
when assigning gender, while the older children took into account semantic and syntactic cues as well. The younger children used syntactic cues when there was no discord with the phonological cues. Older children could use them correctly in cases of discord, but tended to be more accurate when there was accord. Like the French-speakers, they did better on masculine items. The immersion program children, though, were less accurate than the native speakers in their gender assignment. They also possessed an unstable article system, using for example the feminine indefinite article une and the masculine definite article le with the same nouns. Their understanding of masculine articles improved with time, while confusion about the feminine article system continued. The younger children tended to omit articles and children of all ages avoided marking adjectives for gender, using the masculine as a neutral form.

In another procedure modeled after that of Karmiloff-Smith (1979), Cain, et al. (1987), compared the ability to deal with a number of cues on the part of Spanish-speaking children (ages 3-12) and English-speaking adults learning Spanish as a second language. Developmental progression was found in both groups, with the younger children's performance surpassed by both the older children and the higher level L2 adults. The younger L1 children were dependent on a phonological strategy, whereas the older children and L2 learners at every level took natural gender and syntactic cues into consideration when there was discord with suffixes. The ability of even the least proficient adults to cope with cue discord suggests to the authors that "even with a modicum of formal instruction in L2, adults are able to employ successfully the 'standby' procedures that older L1 learners use to resolve linguistic conflict" (Cain, et al., 1987, p. 351).

Marinova-Todd (1994, as cited in Bialystok, 1997) looked at differences in gender assignment strategies between native English and German speakers learning French at a Canadian university. The results of two of the three tasks, the first designed to determine the students' ability to choose the correct article for familiar French nouns in a translation exercise, the second to investigate their skill at assigning gender to nonce French nouns, revealed no differences between the two groups. On the second task, both groups demonstrated ability to assign gender based on the phonological features of nouns. Differences emerged in the third task in which they had to resolve gender conflict between cues in the noun ending and cues to natural gender. Quite unlike the older children in the Stevens study (1984) and the adults in the Cain, et al. study (1987), the English-speaking students ignored the natural gender of the referent and based their decisions on the phonological shape of the noun, as did the younger participants in KarmiloffSmith's study (1979), while the German-speakers applied the more mature strategy of the older Frenchspeaking children, one in which semantic cues were taken into consideration as well. The difference in behavior exhibited by the English and German speakers in this study suggests that the strategies L2 learners use in dealing with gender conflict are influenced by their L1 background. It is unclear, though, why the participants in this study behaved so differently from the more mature participants, also of English-language background, in the Stevens and Cain, et al. studies.

In her analysis of transcripts of interviews of English-dominant, French-dominant, and monolingual French-speaking Canadian children in the 2nd and 5th grades, Harley (1979) found that while the French-dominant and monolingual French speakers made very few gender errors, the speech of English-dominant children (of both monolingual English and bilingual families) was marked by nonstandard usage of gender. Like the adults studied by Marinova-Todd (1994, as cited in Bialystok, 1997) and the younger children in the Stevens (1984) study, the 2nd-grade children attending a French immersion program did not follow a semantic strategy in their assignment of gender. They tended to overgeneralize the masculine to nouns with female referents, e.g., ${ }^{*}$ mon soeur, ${ }^{*}$ le petit fille, though they occasionally assigned nouns with masculine referents to the feminine as well, e.g., * ma frère. By the 5th grade, this tendency had diminished and they made only occasional errors of this type, though still more 
than their French-dominant counterparts. The English-dominant children appeared sensitive to morphophonological cues in noun endings, though less so than the French-dominant children.

Whereas Cain, et al. (1987), Harley (1979), and Stevens (1984) found that the L2 adults and older children in their studies took natural gender cues into consideration in cases in which native speakers would also make use of them, Delisle (1985), in her study of American university students' assignment of gender to English loan words in German, found that these L2 learners used a semantic strategy which would not be employed by native speakers. Germans have been shown to assign gender to loan words based on the morphology of suffixes, e.g., -er (m),-ion (f). When this strategy is unavailable, gender is assigned based on analogy with the nearest lexical item in German, e.g., cover-girl is assigned neutral gender because of analogy with the neuter Mädchen (girl), or the noun is assigned the unmarked masculine form. Delisle's subjects showed a certain amount of sensitivity to noun endings, but morphological cues were overridden by the presence of natural gender cues. For example, words ending in -er were correctly assigned to the masculine unless they referred to women (e.g., stripper) or to things associated with women (e.g., eye-liner), in which case, the American students adopted a semantic approach, i.e., they assigned these nouns to the feminine. Though the L2 learners relied mostly on semantic cues in the beginning, they appeared to become more sensitive to morphological cues over time. Perhaps because of their limited repertoire of German vocabulary, these non-native speakers did not use the nearest lexical equivalent strategy.

Like Cain, et al. (1987), Delisle (1985), Harley (1979) and Stevens (1984), Finneman (1992) found evidence that the participants in his study were using semantic cues in order to assign gender to nouns. In oral interviews with three American university students of Spanish at the beginning level, he observed high agreement rates with nouns referring to the participants themselves and to human female referents. On the other hand, when using Spanish nouns that are generic in reference, but feminine in gender, e.g., gente (people), persona (person), the students used the masculine article to refer to members of either sex (a strategy used by the English-dominant children in Harley's (1979) study as well). Although they exhibited individual differences in how they approached gender, all were aware of the strong gender associations of the endings $-o(\mathrm{~m})$ and $-a(\mathrm{f})$, while they showed a limited degree of understanding of the gender cues in suffixes. The masculine singular form functioned as the default category for all three students.

Rogers (1987) looked at how English university students use grammatical gender in their writing of essays in German and found that considerable difficulty with gender agreement exists even for advanced learners. The number of errors they produced was influenced by the grammatical case in which the noun occurred, e.g., feminine dative was the most problematic. Thus, it appears that in German the acquisition of grammatical gender can not be separated from the development of the case system.

Another example of an L2 learner using grammatical gender quite differently from native speakers is presented by Andersen (1984) in his analysis of an interview of 12-year old Anthony, a child learning Spanish as a second language in Puerto Rico. Anthony, "marks clear inherent gender - sex overtly, clearly, and consistently [...while] he disregards totally all other gender marking" (Andersen, 1984, p. 80). In his interlanguage, there is a one-form, one-meaning correspondence: only one form each of the definite and indefinite articles are used and there is no encoding of gender on articles, determiners, quantifiers, or adjectives. Except for the definite article, $l a$, he uses the masculine form of each of these categories.

Research in the area of acquisition of grammatical gender in the L2 has found both similarities and differences between the ways first and second-language learners approach gender. The difficulty in 
comparing these studies in order to form generalizations lies in the fact that they vary in types of subjects (university students, children), modes of learning (formal, naturalistic), instruments (metalinguistic judgments, elicitation of statements regarding pictures, oral interviews, retrospective interviews, essays), and goals (learning more about learners' strategies, their abilities in assigning gender to lists of words, or their actual production of gender agreement in speech or writing). The fact that the languages under study have different gender systems also complicates the situation. It may be that the L2 itself determines to a certain extent the types of strategies learners will use. For example, Spanish, with its fairly reliable gender marking on noun endings may permit a different approach to gender acquisition than does German, with its three gender system and case marking on nouns, articles, and adjectives. In order to understand how students deal with gender agreement in spontaneous production, it is helpful to first have a clearer picture of how they take account of competing cues in order to assign gender. From the research of Cain, et al. (1987) and Stevens (1984) on L2 learners' ability to cope with various combinations of morphophonological, syntactic, and semantic cues, it appears that adolescents and adult English speakers are able to process all three types, while the Marinova-Todd study (1994, as cited in Bialystok, 1997) suggests otherwise. Thus this issue is far from resolved. Much more research on the cue sensitivity of learners of different L2s will be required before any conclusions can be drawn.

\section{Statement of purpose}

\section{Rationale}

The goal of this study was to look at the sensitivity to morphophonological, syntactic, and semantic cues to gender exhibited by L2 learners of Italian. While L2 learners' strategies with Spanish, French, and German gender have been investigated, there has been no research on the acquisition of grammatical gender by learners of Italian as a foreign language. Because of its particular grammatical gender system, Italian provides a fertile testing ground of ability to deal with conflicting cues.

\section{Italian gender system}

Italian nouns are divided into two genders: masculine and feminine. ${ }^{1}$ The vast majority of singular nouns end in $-o$ or $-a$. Those ending in $-o$ are almost always masculine, e.g., libro (book), while those ending in $-a$ are predominately feminine, e.g., penna (pen). Nouns ending in $-o$ usually take $-i$ in the plural, e.g., libri (books) and those ending in -a usually take -e, e.g., penne (pens). There are a small number of words ending in $-o$ and $-a$ which have irregular plurals. For example, the feminine ala (wing) takes $-i$ in the plural, ali, though it remains feminine, while the masculine ditto (finger) becomes feminine in the plural, dita. A number of nouns end in- $e$ in the singular and in $-i$ in the plural, e.g., frase/frasi (sentence/sentences). In most cases, they are considered unpredictable as to gender. A small group of nouns end in $-i$ in the singular, e.g., crisi (crisis), and an even smaller group in $u$, e.g., virtù (virtue). Both types are usually feminine and remain unchanged in the plural. Nouns ending in consonants, usually loan words, are almost always masculine, e.g., film. They remain invariable in the plural. In summary, -o/$i$ are strongly associated with the masculine and $-a /-e$ with the feminine, although there are numerous exceptions to this tendency.

Certain derivational suffixes are associated with gender as well. Several end in -e, which alone does not clearly mark gender. Examples of suffixes ending in - $e$ are -tore, which is masculine, and -trice

1 The following discussion is based on information regarding gender in Dardano and Tritone's Grammatica Italiana (1989). 
which is feminine, as in attore/attrice (actor/actress). The suffix -sione/-zione is almost always feminine, e.g., nazione (nation), while the augmentative suffix -one is masculine, e.g., cartone (cardboard). While not a suffix, the ending -ma also indicates gender. Nouns of Greek origin with this ending are masculine, e.g., programma (program).

In certain cases, the same form has two meanings which correspond to different genders. For example, il fronte is a "war front," while la fronte means "forehead."

The gender of compound nouns does not always correspond to the usual gender association of its final letter. Many compound nouns ending in $-a$ are masculine, e.g., il retroterra (inland). When made up of two nouns, a compound noun can take either the gender of the first or second noun. For example the word caposquadra (team captain) is masculine, while banconota (banknote) is feminine.

Grammatical gender usually corresponds to the natural gender of nouns referring to people and animals, though there are many examples to the contrary. Natural gender can be indicated in a number of ways: (a) Different endings in nouns are added to the same root to distinguish between genders, e.g., ragazzo/ragazza (boy/girls), signore/signora (gentleman/lady); (b) A masculine noun is made feminine by the addition of a suffix, e.g., studente/studentessa (male student/female student); (c) There are two forms with different roots, e.g., uomo (man), donna (woman); (d) There is one form which can be either masculine or feminine depending on the referent. The gender becomes apparent through the choice of article (or other syntactic agreement). This is the case with some nouns ending in $-e,-a$, and the derivational suffixes -ista/-cida. For example, the masculine article $i l$ indicates that the following nouns refer to males: il cantante (the singer), il collega (the colleague), il pianista (the pianist), il fratricida (the fratricide), while reference to females is indicated by using the feminine article la; (e) One form and one gender is used to refer to both sexes, e.g., la pantera (the panther), il sindaco (the mayor). This is the case of many professions that were once largely the domain of men, where the masculine is used for both sexes, e.g., il giudice (the judge), il primo ministro (the prime minister).

Certain other semantic categories correspond in large part with gender as well (e.g., days of the week, fruit trees, colors). Often the gender of these categories is also in harmony with their morphophonological endings, but there are many cases in which the semantic cue overrides the cue in the noun ending. For example, as a member of the category "color," il rosa (pink) is masculine despite its final $-a$.

Italian requires gender agreement between the noun and its determiners, quantifiers, and most modifying adjectives. Possessive pronouns, as well as subject and object third person singular pronouns also must agree in gender with the noun to which they refer. In certain cases, past participles show agreement with either the subject or object of the sentence. The gender inflections on these parts of speech follow the same pattern as most of Italian nouns, that is, the endings $-0 /-i$ indicate masculine singular/plural, while $-a /-e$ indicate feminine singular/plural. The following are some examples of gender agreement in Italian:

Il mio nuovo libro è stato pubblicato.

'My new book has been published.'

I miei nuovi libri sono stati pubblicati.

'My new books have been published.'

La mia nuova poesia è stata pubblicata.

'My new poem has been published.' 
Le mie nuove poesie sono state pubblicate.

'My new poems have been published.'

The repetition of the same inflectional endings reinforces the cue in the noun ending in the examples above. While most noun endings are associated with one gender or the other, it is the cues in the syntactic agreement which clarify the gender of the noun. They are particularly important in cases where the noun ending is ambiguous, as in nouns ending in -e, or where it is misleading, as in, for example, a word like la mano (the hand). It is possible, though, to have a situation in which there are no cues to agreement in the article or adjective. For example, the gender of a noun like atlante, whose ending gives no clue as to gender, is not clear in the sentence Ho comprato l'atlante verde (I bought the green atlas). This is because of the presence of the article $l^{\prime}$ (used with both masculine and feminine nouns beginning with an article) and an adjective ending in $-e$ (used with both genders).

\section{Research questions}

The specific questions I chose to research regarding L2 learners acquisition of Italian grammatical gender are the following:

1. To what extent do the participants correctly assign grammatical gender based on word-final endings?

2. To what extent do the participants correctly assign grammatical gender based on derivational suffixes?

3. To what extent do the participants correctly assign grammatical gender when given various combinations of morphophonological and syntactic cues?

4. To what extent do the participants correctly assign grammatical gender when cues to natural gender are added to the various combinations of morphophonological and syntactic cues?

5. Is there an order of difficulty based on number and type of cues?

6. Is masculine the unmarked gender?

\section{Hypotheses}

1. Because of the close association between $-o$ and $-a$ endings and masculine and feminine gender, respectively, the participants in this study will correctly assign gender to nouns with these endings. Singular nouns ending in $-i$ will be incorrectly assigned to the masculine because of their association with plural masculine nouns. Likewise, the participants will assign nouns ending in $-e$ to the feminine.

2. They will not assign correct gender to the masculine suffixes ending in - $a$ because of its strong association with the feminine.

3. They will have difficulty when syntactic cues conflict with morphophonological cues, but they will pay more attention to syntactic cues. Cain, et al. (1987) and Stevens (1984) showed in their studies that adolescent and adult L2 learners are capable of using syntactic cues to override contradictory marking on nouns.

4. Given the fact that their mother tongue, English, is a natural gender language, the participants will be influenced by the presence of semantic cues identifying the sex of the referent. 
5. The greater the number of like cues, the easier it will be to correctly identify the gender. Studies have found that there is a higher rate of accuracy when the number of cues was increased for both L1 and L2 speakers (Cain, et al., 1987; Karmiloff-Smith, 1979; PérezPereira, 1991; Stevens, 1984).

6. Masculine, the unmarked gender of Italian, will be the default form in this experiment.

\section{Method}

\section{Participants}

The participants in this study were students in first- and second-year Italian classes at an American university $(n=48)$ and at an American community college $(n=16)$. In order to reflect the normal range of variation in the first two years of a college Italian program, the results of the two groups have been considered together.

\section{Materials}

Materials consisted of three tests of the students' sensitivity to the cues that aid in the determination of the grammatical gender of Italian nouns.

Test 1 (Appendix A) tested the students' ability to assign gender based on morphophonological cues in the noun endings. It required the students to mark as masculine or feminine 38 Italian nouns which they were not expected to know. Subgroup 1 consisted of 24 nouns, with four examples of each of the following endings: $-0,-a,-e,-i,-u,-$ consonant. Subgroup 2 consisted of 14 nouns with two examples of each of the following derivational suffixes: -cida, -ista,-one, -sione/-zione, -tore, and -trice. The gender of the items chosen reflected that which is usually associated with these endings, e.g., all items ending in - $O$ were masculine. The ambiguous $-e$ ending had two items each of both genders. Responses were considered correct if they reflected the actual gender of the nouns tested, with the exception of nouns ending in -cida and -ista. While these suffixes can actually be used with either gender depending on the sex of the referent, they were considered masculine for the purposes of determining the students' awareness of the ability of the morphological cue to override the cue in the word-final letter. Similarly, the ending - $m a$, usually masculine, was also included in this group although it is not technically a suffix.

Test 2 (Appendix B) tested the students' ability to assign gender based on morphophonological cues in the noun ending and syntactic cues in the article. It required the students to mark as masculine or feminine 18 Italian nouns, which the students were not expected to know, presented along with the corresponding definite articles. Five types of article/noun combinations were included. The categories were 2 like cues (cues to the same gender in both article and noun); 1 cue - syntactic (cue in the article and none in the noun ending); 1 cue - morphophonological (cue in the noun ending and none in the article); conflicting cues (cues in the article and the noun ending were in discord); no cues (neither article nor noun ending exhibited cues to gender). The gender-marked articles were $i l(\mathrm{~m})$ and $l a(\mathrm{f})$. The cues on noun endings were $-o(\mathrm{~m})$ and $-a(\mathrm{f})$. The article without a cue was $l^{\prime}$ and nouns ending in the ambiguous $-e$ were considered lacking a gender cue. There were four examples of each type ( 2 feminine $/ 2$ masculine) with the exception of no cues, of which there were two examples ( 1 feminine/1 masculine).

Test 3 (Appendix C) tested the students' ability with a combination of morphophonological cues in the noun ending, syntactic cues in the article, and semantic cues in the form of clearly masculine or feminine names referring to people. It required the students to choose between the masculine and 
feminine forms of an adjective in 21 sentences. The adjective was to agree with the noun it modified. There was a correct answer for each item, given that each indefinite article was marked for gender, i.e., un (m) or una (f). Each noun ended in either an -o, suggesting it was masculine, an - $a$, suggesting it was feminine, or an $-e$, which is unpredictable as to gender. Four combinations of marking for natural gender, article, and noun were given. In the first combination, the three cues were in accord, e.g., Lisa è una dattilografa svelto/svelta. In the second, the semantic and syntactic cues were in accord, but there was no cue on the noun, e.g., Vincenzo è un orefice preciso/precisa. In the third, the semantic and syntactic cues were in accord, but there was discord with the cue in the noun, e.g., Alberto è un despota ricco/ricca. Finally, in the fourth category, the syntactic and morphophonological cues were in accord, but there was discord with the semantic cue, e.g., Marta è un soprano famoso/famosa. There were 6 items of each type, three feminine and three masculine, except for the third category, which only had three masculine items, given that this phenomenon does not exist with feminine nouns.

\section{Procedures}

The three tests were given in order - one immediately after the other during regular class time to intact classes. A total of 20 minutes was required. The students were provided with example items before the administration of each test. Tests 1 and 2 were given to the students orally, with the students marking $M$ or $F$ on the numbered test forms provided. Each item was read aloud twice. The students were told that the nouns were singular and that they were not expected to know the correct gender; rather they should guess, not leaving any items blank. Test 3 was given in written form. The students were once again asked to respond to each item, guessing when unsure.

\section{Analyses}

Each student's set of three tests was marked for number of correct answers given. Total percentages were calculated on correct answers for each test, correct answers by gender, and items assigned to the masculine. The results for Test 1 were divided into the two subgroups under investigation: word-final letters and derivational suffixes. For each of the tests, percentages of correct answers were calculated for each cue type and for each item within the various categories. Descriptive statistics were calculated as well for each category of each test. Implicational scaling was used to examine the degree to which the various item types of each test were hierarchical. This procedure, also known as Guttman scaling, has been used to explore order of acquisition among morphemes in English (Andersen, 1976; Brown, 1983). It allows a researcher to ascertain a hierarchical scale of acquisition among a group of language variables, while also ranking the performance of the individuals tested. A minimum performance criterion (e.g., $75 \%$ correct) is chosen and the group of test answers corresponding to a specific language variable, e.g., nouns ending in -0 , which reaches that minimum level is given a score of 1 , while all others are given a score of 0 . The students are ranked by score, from highest to lowest. The language variable, in this case, cue type, can then be ranked by order of difficulty. A coefficient of reproducibility (CR) is calculated, representing "the degree to which a [participant's] total score predicts his overall response pattern" (Brown, 1983, p. 31-32). A coefficient of scalability (CS) is also calculated. This figure "indicates whether a given list of features are truly scalable" (Hatch \& Lazaraton, 1991, p. 212). In order to be considered valid, an implicational scale must have a CR above .90 (Nie et al, 1975, cited in Andersen, 1976 and Brown, 1983) and a CS above .60 (Hatch \& Lazaraton, 1991). If the variables are scalable, then a participant who performs well on a difficult item should perform well on all of the easier items as well (Nie et al, 1975, cited in Brown, 1983). 


\section{Results}

The total correct assignment of gender given on each of the three tests (see Table 1) indicates that the students' ability to determine gender of unknown words increased markedly from Test 1 (nouns only) to Test 2 (nouns and articles). They performed slightly better on Test 3 than on Test 2, but given the different medium of the tests, the results are not comparable.

Table 1: Correct gender assignment by test $(\%)$

\begin{tabular}{c||c}
\hline test 1 & 53.7 \\
\hline test 2 & 82.6 \\
\hline test 3 & 85.5 \\
\hline
\end{tabular}

On each test, the participants gave correct answers more often when the noun in question was feminine than when it was masculine (see Table 2), and they assigned masculine gender less often than it actually occurred (see Table 3).

Table 2: Correct gender assignment to masculine and feminine items (\%)

\begin{tabular}{r|cc}
\cline { 2 - 3 } & masculine & feminine \\
\hline test 1 & 53 & 55 \\
\hline test 2 & 81 & 84 \\
\hline test 3 & 84 & 88 \\
\hline combined tests & 68 & 70 \\
\hline
\end{tabular}

Table 3: Assignment to masculine by test (\%)

\begin{tabular}{r|cc}
\cline { 2 - 3 } & students' assignment & actual assignment \\
\hline test 1 & 49 & 53 \\
\hline test 2 & 48 & 50 \\
\hline test 3 & 53 & 57 \\
\hline combined tests & 50 & 53 \\
\hline
\end{tabular}

Test 1 was examined for total correct gender assignment by word-final ending (see Table 4). This breakdown demonstrates that the results are not based on chance as the percentage of total correct answers in Table 1 might suggest (53.7\%). Following the general rule in Italian, the students assigned nouns ending in $-o$ to the masculine and those ending in $-a$ to the feminine on almost every test item. Nouns ending in -consonant were correctly assigned to the masculine in the majority of cases, while those terminating in $-i$ and $-u$, were incorrectly perceived as being masculine. The unpredictable final $-e$ was correctly assigned gender around $50 \%$ of the time. Although nouns ending in $-e$ were evenly divided between the two genders on the test, an analysis of how the students assigned gender to these words (see Table 5) indicates that they perceived $-e$ as more indicative of the feminine. 
Table 4: Test 1: Total correct by word-final ending (\%)

\begin{tabular}{cccccc}
\hline $\boldsymbol{- o}(\mathrm{m})$ & $\boldsymbol{- a ( \mathrm { f } )}$ & -consonant $(\mathrm{m})$ & $-\boldsymbol{e}(\mathrm{m} / \mathbf{f})$ & $-\boldsymbol{i}(\mathbf{f})$ & $-u(\mathbf{f})$ \\
\hline \hline 99.6 & 97.7 & 82.0 & 49.6 & 28.1 & 19.9 \\
\hline
\end{tabular}

Table 5: Test 1: Assignment of $-e$ to masculine and feminine (\%)

\begin{tabular}{r|cc}
\hline \multicolumn{1}{c|}{ item } & masculine & feminine \\
\hline selce $(\mathrm{f})$ & 34 & 66 \\
\hline varice $(\mathrm{f})$ & 31 & 69 \\
\hline fortunale $(\mathrm{m})$ & 30 & 70 \\
\hline lendine $(\mathrm{m})$ & 34 & 66 \\
\hline total & 32 & 68 \\
\hline
\end{tabular}

Descriptive statistics were calculated for each word-final ending (see Table 6). Items for $-o$ and $-a$ were negatively skewed with little dispersion of the scores. The category -consonant was also negatively skewed, but with a higher range and $S D$ than those of the two previous categories. The items for $-e$ were slightly positively skewed, but with the distribution closest to normal of the various categories. Both $-i$ and $-u$ were positively skewed and exhibited the greatest amount of dispersion among the six categories.

Table 6: Test 1: Descriptive statistics (word-final endings)

\begin{tabular}{r|rrrrrr}
\cline { 2 - 7 } & $\boldsymbol{- o}$ & $\boldsymbol{- a}$ & -consonant & $\boldsymbol{- e}$ & $\boldsymbol{- i}$ & $\boldsymbol{- u}$ \\
\hline$n$ & 64.00 & 64.00 & 64.00 & 64.00 & 64.00 & 64.00 \\
\hline$k$ & 4.00 & 4.00 & 4.00 & 4.00 & 4.00 & 4.00 \\
\hline mean & 3.98 & 3.91 & 3.28 & 1.98 & 1.13 & 0.80 \\
\hline mode & 4.00 & 4.00 & 4.00 & 2.00 & 0.00 & 0.00 \\
\hline median & 4.00 & 4.00 & 4.00 & 2.00 & 1.00 & 0.00 \\
\hline$S D$ & 0.13 & 0.29 & 0.90 & 0.79 & 1.11 & 1.14 \\
\hline skewedness & -8.00 & -2.85 & -1.00 & 0.03 & 0.62 & 1.33 \\
\hline range & 1.00 & 1.00 & 3.00 & 4.00 & 4.00 & 4.00 \\
\hline high & 4.00 & 4.00 & 4.00 & 4.00 & 4.00 & 4.00 \\
\hline low & 3.00 & 3.00 & 1.00 & 0.00 & 0.00 & 0.00 \\
\hline
\end{tabular}

An analysis of assignment of gender to individual items within each category (Appendix A) shows little variation among percentage of correct answers for items within the categories $-o(2$ percentage points), $-a$ (5 percentage points), and $-u$ (6 percentage points). For items ending in $-u$, the fact that all items except one ( $\mathrm{gru}$ ) ended in the stressed final syllable, -t $\grave{u}$, did not appear to have an effect. Variance on $-e$ items was expected given that there were two feminine and two masculine items. One item in the -consonant category smoking (tuxedo) was assigned to the masculine at a much higher rate (97\%) than the other members of its class (75-80\%). Variation was also seen in the $-i$ category, with the noun elettrolisi (electrolysis) being assigned to the feminine at a rate of $19 \%$, while the other three ranged from $30-34 \%$. 
Implicational scaling was performed on word-final endings at both 75 and $100 \%$ criterion levels in order to determine a scale of difficulty (see Table 7). The categories $-o$ and $-a$ were collapsed into one group, as were $-i$ and $-u$, since it appeared that they were of very similar levels of difficulty. The scales were valid at both criterion levels, with $\mathrm{CR}=.97$ and $\mathrm{CS}=.94$ at the $75 \%$ level and $\mathrm{CR}=.96$ and $\mathrm{CS}=.94$ at the $100 \%$ level. At $75 \%$, the order of difficulty from least to most was $-o /-a<-$ consonant $<-e<-i /-u$. At $100 \%-o /-a$ was easier than -consonant, while the differences between $-e$ and $-i /-u$ disappeared with a sum of zero for both categories.

Table 7: Test 1: Implicational scaling of word-final endings

\begin{tabular}{|c|c|c|c|c|c|c|c|c|c|c|c|c|c|}
\hline \multicolumn{9}{|c|}{$100 \%$} & \multicolumn{5}{|c|}{$75 \%$} \\
\hline ID & o/a & cons & e & $\mathrm{i} / \mathrm{u}$ & sum & error & ID & o/a & cons & e & $\mathrm{i} / \mathbf{u}$ & sum & error \\
\hline 4 & $\overline{1} 1$ & 1 & 0 & 0 & 2 & $\overline{0}$ & 4 & $\overline{1}$ & 1 & 1 & $\overline{0}$ & 3 & $\overline{0}$ \\
\hline 6 & 1 & 1 & 0 & 0 & 2 & 0 & 5 & 1 & 1 & 1 & 0 & 3 & 0 \\
\hline 10 & 1 & 1 & 0 & 0 & 2 & 0 & 8 & 1 & 1 & 1 & 0 & 3 & 0 \\
\hline 12 & 1 & 1 & 0 & 0 & 2 & 0 & 19 & 1 & 1 & 1 & 0 & 3 & 0 \\
\hline 13 & 1 & 1 & 0 & 0 & 2 & 0 & 30 & 1 & 1 & 1 & 0 & 3 & 0 \\
\hline 14 & 1 & 1 & 0 & 0 & 2 & 0 & 31 & 1 & 1 & 1 & 0 & 3 & 0 \\
\hline 15 & 1 & 1 & 0 & 0 & 2 & 0 & 32 & 1 & 1 & 1 & 0 & 3 & 0 \\
\hline 17 & 1 & 1 & 0 & 0 & 2 & 0 & 36 & 1 & 1 & 1 & 0 & 3 & 0 \\
\hline 18 & 1 & 1 & 0 & 0 & 2 & 0 & 44 & 1 & 1 & 1 & 0 & 3 & 0 \\
\hline 19 & 1 & 1 & 0 & 0 & 2 & 0 & 45 & 1 & 1 & 1 & 0 & 3 & 0 \\
\hline 22 & 1 & 1 & 0 & 0 & 2 & 0 & 58 & 1 & 1 & 1 & 0 & 3 & 0 \\
\hline 24 & 1 & 1 & 0 & 0 & 2 & 0 & 59 & 1 & 1 & 1 & 0 & 3 & 0 \\
\hline 25 & 1 & 1 & 0 & 0 & 2 & 0 & 60 & 1 & 1 & 1 & 0 & 3 & 0 \\
\hline 33 & 1 & 1 & 0 & 0 & 2 & 0 & 12 & 1 & 1 & 0 & 0 & 2 & 0 \\
\hline 34 & 1 & 1 & 0 & 0 & 2 & 0 & 13 & 1 & 1 & 0 & 0 & 2 & 0 \\
\hline 42 & 1 & 1 & 0 & 0 & 2 & 0 & 15 & 1 & 1 & 0 & 0 & 2 & 0 \\
\hline 43 & 1 & 1 & 0 & 0 & 2 & 0 & 17 & 1 & 1 & 0 & 0 & 2 & 0 \\
\hline 44 & 1 & 1 & 0 & 0 & 2 & 0 & 18 & 1 & 1 & 0 & 0 & 2 & 0 \\
\hline 45 & 1 & 1 & 0 & 0 & 2 & 0 & 6 & 1 & 1 & 0 & 0 & 2 & 0 \\
\hline 46 & 1 & 1 & 0 & 0 & 2 & 0 & 9 & 1 & 1 & 0 & 0 & 2 & 0 \\
\hline 50 & 1 & 1 & 0 & 0 & 2 & 0 & 20 & 1 & 1 & 0 & 0 & 2 & 0 \\
\hline 55 & 1 & 1 & 0 & 0 & 2 & 0 & 22 & 1 & 1 & 0 & 0 & 2 & 0 \\
\hline 59 & 1 & 1 & 0 & 0 & 2 & 0 & 24 & 1 & 1 & 0 & 0 & 2 & 0 \\
\hline 61 & 1 & 1 & 0 & 0 & 2 & 0 & 25 & 1 & 1 & 0 & 0 & 2 & 0 \\
\hline 62 & 1 & 1 & 0 & 0 & 2 & 0 & 26 & 1 & 1 & 0 & 0 & 2 & 0 \\
\hline 63 & 1 & 1 & 0 & 0 & 2 & 0 & 27 & 1 & 1 & 0 & 0 & 2 & 0 \\
\hline 64 & 1 & 1 & 0 & 0 & 2 & 0 & 28 & 1 & 1 & 0 & 0 & 2 & 0 \\
\hline 2 & 1 & 0 & 0 & 0 & 1 & 0 & 34 & 1 & 1 & 0 & 0 & 2 & 0 \\
\hline 3 & 1 & 0 & 0 & 0 & 1 & 0 & 35 & 1 & 1 & 0 & 0 & 2 & 0 \\
\hline 7 & 1 & 0 & 0 & 0 & 1 & 0 & 37 & 1 & 1 & 0 & 0 & 2 & 0 \\
\hline 8 & 1 & 0 & 0 & 0 & 1 & 0 & 39 & 1 & 1 & 0 & 0 & 2 & 0 \\
\hline 9 & 1 & 0 & 0 & 0 & 1 & 0 & 41 & 1 & 1 & 0 & 0 & 2 & 0 \\
\hline 11 & 1 & 0 & 0 & 0 & 1 & 0 & 42 & 1 & 1 & 0 & 0 & 2 & 0 \\
\hline 16 & 1 & 0 & 0 & 0 & 1 & 0 & 43 & 1 & 1 & 0 & 0 & 2 & 0 \\
\hline 21 & 1 & 0 & 0 & 0 & 1 & 0 & 46 & 1 & 1 & 0 & 0 & 2 & 0 \\
\hline 23 & 1 & 0 & 0 & 0 & 1 & 0 & 48 & 1 & 1 & 0 & 0 & 2 & 0 \\
\hline 27 & 1 & 0 & 0 & 0 & 1 & 0 & 49 & 1 & 1 & 0 & 0 & 2 & 0 \\
\hline 28 & 1 & 0 & 0 & 0 & 1 & 0 & 50 & 1 & 1 & 0 & 0 & 2 & 0 \\
\hline 29 & 1 & 0 & 0 & 0 & 1 & 0 & 51 & 1 & 1 & 0 & 0 & 2 & 0 \\
\hline 31 & 1 & 0 & 0 & 0 & 1 & 0 & 52 & 1 & 1 & 0 & 0 & 2 & 0 \\
\hline 32 & 1 & 0 & 0 & 0 & 1 & 0 & 53 & 1 & 1 & 0 & 0 & 2 & 0 \\
\hline 35 & 1 & 0 & 0 & 0 & 1 & 0 & 56 & 1 & 1 & 0 & 0 & 2 & 0 \\
\hline 36 & 1 & 0 & 0 & 0 & 1 & 0 & 57 & 1 & 1 & 0 & 0 & 2 & 0 \\
\hline 37 & 1 & 0 & 0 & 0 & 1 & 0 & 62 & 1 & 1 & 0 & 0 & 2 & 0 \\
\hline 39 & 1 & 0 & 0 & 0 & 1 & 0 & 63 & 1 & 1 & 0 & 0 & 2 & 0 \\
\hline
\end{tabular}


Table 7 (cont.): Test 1: Implicational scaling of word-final endings

\begin{tabular}{|c|c|c|c|c|c|c|c|c|c|c|c|c|c|}
\hline 40 & 1 & 0 & 0 & 0 & 1 & 0 & 64 & 1 & 1 & 0 & 0 & 2 & 0 \\
\hline 47 & 1 & 0 & 0 & 0 & 1 & 0 & 61 & 1 & 1 & 0 & 0 & 2 & 0 \\
\hline 48 & 1 & 0 & 0 & 0 & 1 & 0 & 7 & 1 & (0) & - & 0 & 2 & 2 \\
\hline 52 & 1 & 0 & 0 & 0 & 1 & 0 & 21 & 1 & (0) & - & 0 & 2 & 2 \\
\hline 53 & 1 & 0 & 0 & 0 & 1 & 0 & 38 & 1 & (0) & - & 0 & 2 & 2 \\
\hline 54 & 1 & 0 & 0 & 0 & 1 & 0 & 1 & 1 & 0 & 0 & 0 & 1 & 0 \\
\hline 56 & 1 & 0 & 0 & 0 & 1 & 0 & 2 & 1 & 0 & 0 & 0 & 1 & 0 \\
\hline 57 & 1 & 0 & 0 & 0 & 1 & 0 & 3 & 1 & 0 & 0 & 0 & 1 & 0 \\
\hline 60 & 1 & 0 & 0 & 0 & 1 & 0 & 11 & 1 & 0 & 0 & 0 & 1 & 0 \\
\hline 41 & (0) & - & 0 & 0 & 1 & 2 & 16 & 1 & 0 & 0 & 0 & 1 & 0 \\
\hline 49 & (0) & - & 0 & 0 & 1 & 2 & 23 & 1 & 0 & 0 & 0 & 1 & 0 \\
\hline 51 & (0) & - & 0 & 0 & 1 & 2 & 40 & 1 & 0 & 0 & 0 & 1 & 0 \\
\hline 58 & (0) & 1 & 0 & 0 & 1 & 2 & 47 & 1 & 0 & 0 & 0 & 1 & 0 \\
\hline 20 & 0 & 0 & 0 & 0 & 0 & 0 & 53 & 1 & 0 & 0 & 0 & 1 & 0 \\
\hline 38 & 0 & 0 & 0 & 0 & 0 & 0 & 54 & 1 & 0 & 0 & 0 & 1 & 0 \\
\hline sum & 57 & 34 & 1 & 0 & 92 & 10 & sum & 64 & 51 & 16 & 1 & 132 & 8 \\
\hline $\mathrm{p}$ & .89 & .53 & .02 & .00 & & & $p$ & 1.00 & .80 & $.2 !$ & .02 & & \\
\hline$q$ & .11 & .47 & .98 & 1.00 & & & $q$ & .00 & .20 & $.7 !$ & .98 & & \\
\hline CR & .96 & & & & & & CR & .97 & & & & & \\
\hline MMR & .36 & & & & & & MMR & .52 & & & & & \\
\hline PI & .60 & & & & & & PI & .45 & & & & & \\
\hline CS & .94 & & & & & & CS & .94 & & & & & \\
\hline
\end{tabular}

The percentage of total correct answers for the assignment of gender to nouns with derivational suffixes (see Table 8 ) shows limited sensitivity to morphophonological cues in the noun endings. The participants appeared more aware of gender cues in derivational suffixes ending in - $e$ than they were of those ending in $-a$, which, contrary to the general rule, indicate the masculine. Scores for the latter are extremely low. There appears to have been a minimal awareness of the masculine gender cue in -ista and - $m a$, while -cida does not seem to have been perceived as masculine. The feminine suffix -trice $(74.2 \%)$ appears to be a stronger cue than the $-e$ on nouns without a suffix, which had an average assignment rate of $68 \%$ to the feminine and $32 \%$ to the masculine on Test 1 (see Table 5), while the score for the feminine suffixes -sione/-zione is slightly lower (60.9\%). Sensitivity to the masculine gender cue in -tore is demonstrated by the fact that it is assigned to the masculine at a much higher rate $(63.3 \%)$ than it was to nouns ending in -e (see Table 5). This is also true to a lesser extent of the masculine -one, assigned to the masculine at $43 \%$.

Table 8: $\quad$ Test 1: Total correct by derivational suffix (\%)

\begin{tabular}{ccccccc}
\hline -trice(f) & -tore $(\mathrm{m})$ & $\begin{array}{c}\text {-sionel } \\
\text {-zione }(\mathrm{f})\end{array}$ & -one $(\mathrm{m})$ & - $\boldsymbol{m a}(\mathrm{m})$ & -ista $(\mathrm{m})$ & -cida $(\mathrm{m})$ \\
\hline \hline 74.2 & 63.3 & 60.9 & 43.0 & 13.3 & 9.4 & 1.6 \\
\hline
\end{tabular}

The descriptive statistics of the derivational suffix categories (see Table 9) reveal that -trice is negatively skewed, while the others are positively skewed, though only slightly in the case of -one, which has a more normal distribution. The range for all categories was the maximum of 2, except for -cida which had a range of 1 . Unfortunately, these statistics can reveal little dispersion of scores given the small number of items. 
Table 9: Test 1: Descriptive statistics (derivational suffixes)

\begin{tabular}{r||rrrrrrr}
\cline { 2 - 8 } & -trice & -tore & $\begin{array}{l}\text {-sionel } \\
\text {-zione }\end{array}$ & -one & - ma & -ista & -cida \\
\hline$n$ & 64.00 & 64.00 & 64.00 & 64.00 & 64.00 & 64.00 & 64.00 \\
\hline$k$ & 2.00 & 2.00 & 2.00 & 2.00 & 2.00 & 2.00 & 2.00 \\
\hline mean & 1.50 & 1.30 & 1.20 & 0.90 & 0.30 & 0.20 & 0.00 \\
\hline mode & 2.00 & 2.00 & 1.50 & 1.00 & 0.00 & 0.00 & 0.00 \\
\hline median & 2.00 & 1.00 & 2.00 & 1.00 & 0.00 & 0.00 & 0.00 \\
\hline$S D$ & 0.70 & 0.80 & 0.90 & 0.70 & 0.60 & 0.50 & 0.20 \\
\hline skewedness & -1.10 & 1.50 & 1.40 & 0.20 & 2.10 & 2.80 & 5.50 \\
\hline range & 2.00 & 2.00 & 2.00 & 2.00 & 2.00 & 2.00 & 1.00 \\
\hline high & 2.00 & 2.00 & 2.00 & 2.00 & 2.00 & 2.00 & 1.00 \\
\hline low & 0.00 & 0.00 & 0.00 & 0.00 & 0.00 & 0.00 & 0.00 \\
\hline
\end{tabular}

An analysis of items within each category (Appendix A) shows little or no variation on the items for - $m a$ and -cida., while items for the categories -trice, tore, sione/zione, and -ista vary from (6 to 11 percentage points). The two items for -one are treated quite differently: festone 's assignment to the masculine $(27 \%)$ is slightly lower than are the items for $-e$ which do not have a derivational suffix (32\%) while the noun mollettone (thick flannel) is assigned to the masculine at $59 \%$. More items are needed to clarify how students behave with -one, as it is not clear what caused the difference in assignment rates for the two items.

Implicational scaling of the derivational suffixes was performed, but a clear scale failed to emerge from the data $(\mathrm{CR}=.54$ and $\mathrm{CS}=.46$ at $100 \%$ criterion level).

The results for Test 2 (Table 10) show that students have little difficulty with gender assignment when they are supplied complementary syntactic and morphophonological cues. Removing the morphophonological cue caused a slight decrease in scores. It appears that assigning gender when there was a morphophonological cue without a syntactic cue was of similar difficulty to doing so when the two cues were in conflict. The most difficult, not surprisingly, are those items without either type of cue.

Table 10: Test 2: Total correct by cue type

\begin{tabular}{r|c}
\multicolumn{1}{c|}{ cue type } & \% correct \\
\hline 2 like cues & 99.2 \\
\hline 1 cue - syntactic & 96.1 \\
\hline 1 cue - morphophonological & 88.3 \\
\hline conflicting cues & 87.9 \\
\hline no cues & 36.7 \\
\hline
\end{tabular}

The descriptive statistics of Test 2 (see Table 11) show that all categories were negatively skewed except for that of no cues. There was little dispersion of scores for items with two like cues. Dispersion increased for items with only a syntactic cue and then again for those with conflicting cues. As the category 1 cue - morphophonological had only two items (for reasons to be explained), the dispersion cannot be compared to the other categories which have four items. The same is true for that of no cues which also has two items. 
Table 11: Test 2: Descriptive statistics

\begin{tabular}{r||ccccc}
\cline { 2 - 6 } & 2 like cues & 1 cue (syn) & conflicting cues & 1 cue (mp) & no cues \\
\hline$n$ & 64.00 & 64.00 & 64.00 & 64.00 & 64.00 \\
\hline$k$ & 4.00 & 4.00 & 4.00 & 2.00 & 2.00 \\
\cline { 2 - 6 } mean & 3.97 & 3.84 & 3.52 & 1.77 & 0.73 \\
\hline mode & 4.00 & 4.00 & 4.00 & 2.00 & 1.00 \\
\hline median & 4.00 & 4.00 & 4.00 & 2.00 & 1.00 \\
\hline$S D$ & 0.18 & 0.41 & 1.01 & 0.43 & 0.60 \\
\hline skewedness & -5.52 & -2.64 & -1.97 & -1.28 & 0.16 \\
\hline range & 1.00 & 2.00 & 4.00 & 1.00 & 2.00 \\
\hline high & 4.00 & 4.00 & 4.00 & 2.00 & 2.00 \\
\hline low & 3.00 & 2.00 & 0.00 & 1.00 & 0.00 \\
\hline
\end{tabular}

An analysis of each category by item (Appendix C) reveals little variation among items for the first two categories ( 2 like cues and 1 cue - syntactic). Scores were slightly lower for masculine items in these categories. There is a range of 7 percentage points among items with conflicting cues. The scores for items l'emolumento and l'ossatura in the 1 cue - morphophonological category were much lower than the other two items and were not calculated for Tables 10 through 12 because of their problematic nature, which will be discussed in the next section. Students did better on the feminine item in the no cues category then they did on the masculine one, though the score is still much lower than those for nouns ending in $-e$ in Test 1 (see Table 5).

Implicational scaling performed at a criterion level of $100 \%$ (Table 12) had a CR of .91 and a CS of .69. The scale showed the following order of difficulty from least to most: 2 like cues< 1 cue - syntactic< conflicting cues $<1$ cue - morphophonological<no cues. There was variation in the scale on the categories of 1 cue - morphophonological and conflicting cues caused by a group of students who performed well on items with the morphophonological cue, while erring on those items with conflicting cues. The scalability improved when the two categories were considered separately (see Table 12). A clear scale emerged $(\mathrm{CR}=.96, \mathrm{CS}=.88)$ when 1 cue - morphonological was excluded and conflicting cues included. The opposite case seen in Table 13 also yielded a valid scale (CR=.92, $\mathrm{CS}=.76)$.

Table 12: Test 2: Implicational scaling of five cue types

\begin{tabular}{c|ccccccc}
\hline ID & $\begin{array}{c}2 \text { like } \\
\text { cues }\end{array}$ & $\begin{array}{c}1 \text { cue } \\
\text { (syn) }\end{array}$ & $\begin{array}{c}\text { conflicting } \\
\text { cues }\end{array}$ & $\begin{array}{c}1 \text { cue } \\
(\mathbf{m p})\end{array}$ & $\begin{array}{c}\text { no } \\
\text { cues }\end{array}$ & sum & error \\
\hline \hline 3 & 1 & 1 & 1 & 1 & 1 & 5 & 0 \\
\hline 14 & 1 & 1 & 1 & 1 & 1 & 5 & 0 \\
\hline 27 & 1 & 1 & 1 & 1 & 1 & 5 & 0 \\
\hline 30 & 1 & 1 & 1 & 1 & 1 & 5 & 0 \\
\hline 55 & 1 & 1 & 1 & 1 & 1 & 5 & 0 \\
\hline 1 & 1 & 1 & 1 & 1 & 0 & 4 & 0 \\
\hline 8 & 1 & 1 & 1 & 1 & 0 & 4 & 0 \\
\hline 9 & 1 & 1 & 1 & 1 & 0 & 4 & 0 \\
\hline 12 & 1 & 1 & 1 & 1 & 0 & 4 & 0 \\
\hline 19 & 1 & 1 & 1 & 1 & 0 & 4 & 0 \\
\hline 20 & 1 & 1 & 1 & 1 & 0 & 4 & 0 \\
\hline 22 & 1 & 1 & 1 & 1 & 0 & 4 & 0 \\
\hline 25 & 1 & 1 & 1 & 1 & 0 & 4 & 0 \\
\hline
\end{tabular}


Table 12 (cont.): Test 2: Implicational scaling of five cue types

\begin{tabular}{|c|c|c|c|c|c|c|c|}
\hline 29 & 1 & 1 & 1 & 1 & 0 & 4 & 0 \\
\hline 35 & 1 & 1 & 1 & 1 & 0 & 4 & 0 \\
\hline 37 & 1 & 1 & 1 & 1 & 0 & 4 & 0 \\
\hline 40 & 1 & 1 & 1 & 1 & 0 & 4 & 0 \\
\hline 41 & 1 & 1 & 1 & 1 & 0 & 4 & 0 \\
\hline 43 & 1 & 1 & 1 & 1 & 0 & 4 & 0 \\
\hline 44 & 1 & 1 & 1 & 1 & 0 & 4 & 0 \\
\hline 45 & 1 & 1 & 1 & 1 & 0 & 4 & 0 \\
\hline 46 & 1 & 1 & 1 & 1 & 0 & 4 & 0 \\
\hline 47 & 1 & 1 & 1 & 1 & 0 & 4 & 0 \\
\hline 49 & 1 & 1 & 1 & 1 & 0 & 4 & 0 \\
\hline 53 & 1 & 1 & 1 & 1 & 0 & 4 & 0 \\
\hline 54 & 1 & 1 & 1 & 1 & 0 & 4 & 0 \\
\hline 57 & 1 & 1 & 1 & 1 & 0 & 4 & 0 \\
\hline 58 & 1 & 1 & 1 & 1 & 0 & 4 & 0 \\
\hline 59 & 1 & 1 & 1 & 1 & 0 & 4 & 0 \\
\hline 61 & 1 & 1 & 1 & 1 & 0 & 4 & 0 \\
\hline 63 & 1 & 1 & 1 & 1 & 0 & 4 & 0 \\
\hline 50 & 1 & 1 & 1 & 1 & 0 & 4 & 0 \\
\hline 56 & 1 & 1 & 1 & 1 & 0 & 4 & 0 \\
\hline 2 & 1 & 1 & 1 & 0 & 0 & 3 & 0 \\
\hline 4 & 1 & 1 & 1 & 0 & 0 & 3 & 0 \\
\hline 11 & 1 & 1 & 1 & 0 & 0 & 3 & 0 \\
\hline 15 & 1 & 1 & 1 & 0 & 0 & 3 & 0 \\
\hline 17 & 1 & 1 & 1 & 0 & 0 & 3 & 0 \\
\hline 23 & 1 & 1 & 1 & 0 & 0 & 3 & 0 \\
\hline 26 & 1 & 1 & 1 & 0 & 0 & 3 & 0 \\
\hline 39 & 1 & 1 & 1 & 0 & 0 & 3 & 0 \\
\hline 51 & 1 & 1 & 1 & 0 & 0 & 3 & 0 \\
\hline 52 & 1 & 1 & 1 & 0 & 0 & 3 & 0 \\
\hline 62 & 1 & 1 & 1 & 0 & 0 & 3 & 0 \\
\hline 64 & 1 & 1 & 1 & 0 & 0 & 3 & 0 \\
\hline 5 & 1 & 1 & (0) & - & 0 & 3 & 2 \\
\hline 13 & 1 & (0) & 1 & - & 0 & 3 & 2 \\
\hline 16 & 1 & 1 & (0) & - & 0 & 3 & 2 \\
\hline 21 & 1 & 1 & (0) & - & 0 & 3 & 2 \\
\hline 24 & 1 & (0) & 1 & - & 0 & 3 & 2 \\
\hline 28 & 1 & 1 & (0) & - & 0 & 3 & 2 \\
\hline 31 & 1 & 1 & $(0)$ & - & 0 & 3 & 2 \\
\hline 32 & (0) & 1 & 1 & - & 0 & 3 & 2 \\
\hline 34 & 1 & (0) & 1 & - & 0 & 3 & 2 \\
\hline 48 & (0) & 1 & 1 & - & 0 & 3 & 2 \\
\hline 60 & 1 & 1 & (0) & - & 0 & 3 & 2 \\
\hline 33 & 1 & 1 & 0 & 0 & 0 & 2 & 0 \\
\hline 36 & 1 & 1 & 0 & 0 & 0 & 2 & 0 \\
\hline 6 & 1 & (0) & 0 & - & 0 & 2 & 2 \\
\hline 7 & 1 & (0) & 0 & - & 0 & 2 & 2 \\
\hline 18 & 1 & $(0)$ & 0 & - & 0 & 2 & 2 \\
\hline 38 & 1 & (0) & 0 & - & 0 & 2 & 2 \\
\hline 42 & 1 & $(0)$ & 0 & - & 0 & 2 & 2 \\
\hline 10 & 1 & 0 & 0 & 0 & 0 & 1 & 0 \\
\hline sum & 62 & 55 & 50 & 49 & 5 & 221 & 30 \\
\hline$p$ & .97 & .86 & .78 & .77 & .08 & & \\
\hline$q$ & .03 & .14 & .22 & .23 & .92 & & \\
\hline CR & .91 & & & & & & \\
\hline MMR & .69 & & & & & & \\
\hline PI & .21 & & & & & & \\
\hline $\mathrm{CS}$ & .69 & & & & & & \\
\hline
\end{tabular}


Table 13: Test 2: Implicational scaling of four cue types

\begin{tabular}{|c|c|c|c|c|c|c|c|c|c|c|c|c|c|}
\hline \multicolumn{14}{|c|}{$100 \%$} \\
\hline ID & $\begin{array}{c}2 \text { like } \\
\text { cues }\end{array}$ & $\begin{array}{l}1 \text { cue } \\
\text { (syn.) }\end{array}$ & $\begin{array}{l}\text { conflict- } \\
\text { ing cues }\end{array}$ & $\begin{array}{c}\text { no } \\
\text { cues }\end{array}$ & sum & error & ID & $\begin{array}{c}2 \text { like } \\
\text { cues }\end{array}$ & $\begin{array}{l}1 \text { cue } \\
\text { (syn.) }\end{array}$ & $\begin{array}{l}\text { conflict- } \\
\text { ing cues }\end{array}$ & $\begin{array}{c}\text { no } \\
\text { cues }\end{array}$ & sum & error \\
\hline 3 & 1 & 1 & 1 & 1 & 4 & 0 & 3 & 1 & 1 & 1 & 1 & 4 & 0 \\
\hline 14 & 1 & 1 & 1 & 1 & 4 & 0 & 14 & 1 & 1 & 1 & 1 & 4 & 0 \\
\hline 27 & 1 & 1 & 1 & 1 & 4 & 0 & 27 & 1 & 1 & 1 & 1 & 4 & 0 \\
\hline 30 & 1 & 1 & 1 & 1 & 4 & 0 & 30 & 1 & 1 & 1 & 1 & 4 & 0 \\
\hline 55 & 1 & 1 & 1 & 1 & 4 & 0 & 55 & 1 & 1 & 1 & 1 & 4 & 0 \\
\hline 1 & 1 & 1 & 1 & 0 & 3 & 0 & 1 & 1 & 1 & 1 & 0 & 3 & 0 \\
\hline 2 & 1 & 1 & 1 & 0 & 3 & 0 & 5 & 1 & 1 & 1 & 0 & 3 & 0 \\
\hline 4 & 1 & 1 & 1 & 0 & 3 & 0 & 8 & 1 & 1 & 1 & 0 & 3 & 0 \\
\hline 8 & 1 & 1 & 1 & 0 & 3 & 0 & 9 & 1 & 1 & 1 & 0 & 3 & 0 \\
\hline 9 & 1 & 1 & 1 & 0 & 3 & 0 & 12 & 1 & 1 & 1 & 0 & 3 & 0 \\
\hline 11 & 1 & 1 & 1 & 0 & 3 & 0 & 16 & 1 & 1 & 1 & 0 & 3 & 0 \\
\hline 12 & 1 & 1 & 1 & 0 & 3 & 0 & 19 & 1 & 1 & 1 & 0 & 3 & 0 \\
\hline 15 & 1 & 1 & 1 & 0 & 3 & 0 & 20 & 1 & 1 & 1 & 0 & 3 & 0 \\
\hline 17 & 1 & 1 & 1 & 0 & 3 & 0 & 21 & 1 & 1 & 1 & 0 & 3 & 0 \\
\hline 19 & 1 & 1 & 1 & 0 & 3 & 0 & 22 & 1 & 1 & 1 & 0 & 3 & 0 \\
\hline 20 & 1 & 1 & 1 & 0 & 3 & 0 & 25 & 1 & 1 & 1 & 0 & 3 & 0 \\
\hline 22 & 1 & 1 & 1 & 0 & 3 & 0 & 28 & 1 & 1 & 1 & 0 & 3 & 0 \\
\hline 23 & 1 & 1 & 1 & 0 & 3 & 0 & 29 & 1 & 1 & 1 & 0 & 3 & 0 \\
\hline 25 & 1 & 1 & 1 & 0 & 3 & 0 & 31 & 1 & 1 & 1 & 0 & 3 & 0 \\
\hline 26 & 1 & 1 & 1 & 0 & 3 & 0 & 35 & 1 & 1 & 1 & 0 & 3 & 0 \\
\hline 29 & 1 & 1 & 1 & 0 & 3 & 0 & 37 & 1 & 1 & 1 & 0 & 3 & 0 \\
\hline 35 & 1 & 1 & 1 & 0 & 3 & 0 & 40 & 1 & 1 & 1 & 0 & 3 & 0 \\
\hline 37 & 1 & 1 & 1 & 0 & 3 & 0 & 41 & 1 & 1 & 1 & 0 & 3 & 0 \\
\hline 39 & 1 & 1 & 1 & 0 & 3 & 0 & 43 & 1 & 1 & 1 & 0 & 3 & 0 \\
\hline 40 & 1 & 1 & 1 & 0 & 3 & 0 & 44 & 1 & 1 & 1 & 0 & 3 & 0 \\
\hline 41 & 1 & 1 & 1 & 0 & 3 & 0 & 45 & 1 & 1 & 1 & 0 & 3 & 0 \\
\hline 43 & 1 & 1 & 1 & 0 & 3 & 0 & 46 & 1 & 1 & 1 & 0 & 3 & 0 \\
\hline 44 & 1 & 1 & 1 & 0 & 3 & 0 & 47 & 1 & 1 & 1 & 0 & 3 & 0 \\
\hline 45 & 1 & 1 & 1 & 0 & 3 & 0 & 49 & 1 & 1 & 1 & 0 & 3 & 0 \\
\hline 46 & 1 & 1 & 1 & 0 & 3 & 0 & 50 & 1 & 1 & 1 & 0 & 3 & 0 \\
\hline 47 & 1 & 1 & 1 & 0 & 3 & 0 & 53 & 1 & 1 & 1 & 0 & 3 & 0 \\
\hline 49 & 1 & 1 & 1 & 0 & 3 & 0 & 54 & 1 & 1 & 1 & 0 & 3 & 0 \\
\hline 50 & 1 & 1 & 1 & 0 & 3 & 0 & 56 & 1 & 1 & 1 & 0 & 3 & 0 \\
\hline 51 & 1 & 1 & 1 & 0 & 3 & 0 & 57 & 1 & 1 & 1 & 0 & 3 & 0 \\
\hline 52 & 1 & 1 & 1 & 0 & 3 & 0 & 58 & 1 & 1 & 1 & 0 & 3 & 0 \\
\hline 53 & 1 & 1 & 1 & 0 & 3 & 0 & 59 & 1 & 1 & 1 & 0 & 3 & 0 \\
\hline 54 & 1 & 1 & 1 & 0 & 3 & 0 & 60 & 1 & 1 & 1 & 0 & 3 & 0 \\
\hline 56 & 1 & 1 & 1 & 0 & 3 & 0 & 61 & 1 & 1 & 1 & 0 & 3 & 0 \\
\hline 57 & 1 & 1 & 1 & 0 & 3 & 0 & 63 & 1 & 1 & 1 & 0 & 3 & 0 \\
\hline 58 & 1 & 1 & 1 & 0 & 3 & 0 & 2 & 1 & 1 & 0 & 0 & 2 & 0 \\
\hline 59 & 1 & 1 & 1 & 0 & 3 & 0 & 4 & 1 & 1 & 0 & 0 & 2 & 0 \\
\hline 61 & 1 & 1 & 1 & 0 & 3 & 0 & 11 & 1 & 1 & 0 & 0 & 2 & 0 \\
\hline 62 & 1 & 1 & 1 & 0 & 3 & 0 & 15 & 1 & 1 & 0 & 0 & 2 & 0 \\
\hline 63 & 1 & 1 & 1 & 0 & 3 & 0 & 17 & 1 & 1 & 0 & 0 & 2 & 0 \\
\hline 64 & 1 & 1 & 1 & 0 & 3 & 0 & 23 & 1 & 1 & 0 & 0 & 2 & 0 \\
\hline 5 & 1 & 1 & 0 & 0 & 2 & 0 & 26 & 1 & 1 & 0 & 0 & 2 & 0 \\
\hline 16 & 1 & 1 & 0 & 0 & 2 & 0 & 33 & 1 & 1 & 0 & 0 & 2 & 0 \\
\hline
\end{tabular}


Table 13 (cont.): Test 2: Implicational scaling of four cue types

\begin{tabular}{|c|c|c|c|c|c|c|c|c|c|c|c|c|c|}
\hline 21 & 1 & 1 & $\overline{0}$ & 0 & 2 & 0 & 36 & 1 & 1 & 0 & 0 & 2 & $\overline{0}$ \\
\hline 28 & 1 & 1 & 0 & 0 & 2 & 0 & 39 & 1 & 1 & 0 & 0 & 2 & 0 \\
\hline 31 & 1 & 1 & 0 & 0 & 2 & 0 & 51 & 1 & 1 & 0 & 0 & 2 & 0 \\
\hline 33 & 1 & 1 & 0 & 0 & 2 & 0 & 52 & 1 & 1 & 0 & 0 & 2 & 0 \\
\hline 36 & 1 & 1 & 0 & 0 & 2 & 0 & 62 & 1 & 1 & 0 & 0 & 2 & 0 \\
\hline 60 & 1 & 1 & 0 & 0 & 2 & 0 & 64 & 1 & 1 & 0 & 0 & 2 & 0 \\
\hline 13 & 1 & (0) & - & 0 & 2 & 2 & 6 & 1 & (0) & - & 0 & 2 & 2 \\
\hline 24 & 1 & (0) & - & 0 & 2 & 2 & 7 & 1 & (0) & - & 0 & 2 & 2 \\
\hline 32 & (0) & 1 & - & 0 & 2 & 2 & 13 & 1 & (0) & - & 0 & 2 & 2 \\
\hline 34 & 1 & (0) & - & 0 & 2 & 2 & 18 & 1 & (0) & - & 0 & 2 & 2 \\
\hline 48 & (0) & 1 & - & 0 & 2 & 2 & 24 & 1 & (0) & - & 0 & 2 & 2 \\
\hline 6 & 1 & 0 & 0 & 0 & 1 & 0 & 32 & (0) & 1 & - & 0 & 2 & 2 \\
\hline 7 & 1 & 0 & 0 & 0 & 1 & 0 & 34 & 1 & (0) & - & 0 & 2 & 2 \\
\hline 10 & 1 & 0 & 0 & 0 & 1 & 0 & 38 & 1 & (0) & - & 0 & 2 & 2 \\
\hline 18 & 1 & 0 & 0 & 0 & 1 & 0 & 42 & 1 & (0) & - & 0 & 2 & 2 \\
\hline 38 & 1 & 0 & 0 & 0 & 1 & 0 & 48 & (0) & 1 & - & 0 & 2 & 2 \\
\hline 42 & 1 & 0 & 0 & 0 & 1 & 0 & 10 & 1 & 0 & 0 & 0 & 1 & 0 \\
\hline sum & 62 & 55 & 50 & 5 & 172 & 10 & sum & 62 & 55 & 49 & 5 & 171 & 20 \\
\hline$p$ & .97 & .86 & .78 & .08 & & & $p$ & .97 & .86 & .77 & .08 & & \\
\hline$q$ & .03 & .14 & .22 & .92 & & & $q$ & .03 & .14 & .23 & .92 & & \\
\hline CR & .96 & & & & & & CR & .92 & & & & & \\
\hline MMR & .67 & & & & & & MMR & .67 & & & & & \\
\hline PI & .29 & & & & & & PI & .25 & & & & & \\
\hline CS & .88 & & & & & & CS & .76 & & & & & \\
\hline
\end{tabular}

In Test 3 (see Table 14), it appears that, when students are given three complementary cues (semantic, syntactic, and morphophonological), they have no difficulty in identifying the correct gender of the adjective. Removing the morphophonological clue lowers the scores slightly. Supplying a noun with a morphophonological ending which is in conflict with the semantic and syntactic cues increases the level of difficulty, but the most problematic is assigning gender when the semantic clue is in conflict with both the syntactic and the morphophonological cues.

Table 14: Test 3: Total correct by cue type (\%)

The first position indicates the syntactic cue on the article, the second position indicates the semantic cue in the form of a person's name, and the third position indicates the morphophonological cue on the noun ending.

\begin{tabular}{r||c}
\hline MMM/FFF & 99.7 \\
\hline MM $/$ FFØ & 96.1 \\
\hline MMF & 76.0 \\
\cline { 2 - 2 } MFM/FMF & 65.4 \\
\hline $\begin{array}{l}\mathrm{M}=\text { masculine } \\
\mathrm{F}=\text { feminine } \\
\varnothing=\text { no gender marking }\end{array}$
\end{tabular}

The descriptive statistics (see Table 15) reveal that each category was positively skewed. There was very little dispersion of scores on items with three like cues. These statistics are very similar to those of items ending in $-o$ and $-a$ in Test 1 (see Table 6) and those with two like cues in Test 2 (see Table 9). Increased dispersion was seen when the cue on the noun was removed. These figures closely approximate those for the syntactic only category in Test 2 (Table 9). Dispersion of scores increased once 
again when the morphophonological cue conflicted with the semantic and syntactic cues, and then again when the semantic gender conflicted with the syntactic and morphophonological cue.

Table 15: Test 3: Descriptive statistics

\begin{tabular}{r||rrrr} 
& MMM/FFF & MMØ/FFØ & MMF & MFM/FMF \\
\hline$n$ & 64.00 & 64.00 & 64.00 & 64.00 \\
\hline$k$ & 6.00 & 6.00 & 3.00 & 6.00 \\
\hline mean & 5.98 & 5.77 & 2.28 & 3.92 \\
\hline mode & 6.00 & 6.00 & 3.00 & 6.00 \\
\hline median & 6.00 & 6.00 & 3.00 & 5.00 \\
\hline$S D$ & 0.13 & 0.64 & 1.05 & 2.52 \\
\hline skewedness & -8.00 & -3.20 & -1.20 & -0.69 \\
\hline range & 1.00 & 3.00 & 3.00 & 6.00 \\
\hline high & 6.00 & 6.00 & 3.00 & 6.00 \\
\hline low & 5.00 & 3.00 & 0.00 & 0.00 \\
\hline
\end{tabular}

Items with 3 like cues show almost no variation, while those lacking the morphophonological cue show a range of 5 percentage points and those in which the semantic cue differed in gender from the other two have a range of 9 percentage points. In the latter, students did slightly less well on items with female referents than they did when the referent was male. Items where the morphophonological cue differed from the syntactic and semantic cues exhibited the greatest range of variation (14 percentage points).

When implicational scaling with a criterion value of $100 \%$ was performed on Test 3 results (see Table 16), the coefficients of reproducibility (.89) and scalability (.59) were slightly under the figures required to be considered a clear scale. The order of difficulty revealed from least to most was cue accord -3 cues<cue accord -2 cues $($ syn $=$ sem, $m p=\varnothing)<c u e$ discord $($ syn=sem $\neq m p)<c u e$ discord $($ syn=mp $\neq$ sem). The scale was recalculated at $66 \%$ criterion level. This revealed a CR of .90 and a low CS of .33. The problem in scalability was created by a group of students who, unlike the others found cue discord easier when the conflicting cue was in the gender of the referent rather than in the noun ending. In order to avoid this problem, the scaling was repeated twice with only three cues (see Table 17). The scale cue accord - 3 cues<cue accord -2 cues $(s y n=s e m, m p=\varnothing)<$ cue discord $($ syn $=$ sem $\neq m p)$ proved to be a perfect scale $(\mathrm{CR}=1.0$, $\mathrm{CS}=1.0)$. Another clear scale ( $\mathrm{CR}=.97 ; \mathrm{CS}=.86)$ emerged with the following order of difficulty: cue accord 3 cues $<$ cue accord -2 cues ( $s y n=s e m, m p=\varnothing$ ) <cue discord ( syn=morp $\neq$ sem).

Table 16: Test 3: Implicational scaling of four cue types

\begin{tabular}{c|ccccccc}
\hline \multicolumn{1}{|c}{$\mathbf{1 0 0 \%}$} \\
\hline \hline ID & MMM/FFF & MMØ/FFØ & MMF & MFM/FMF & sum & error \\
\hline 1 & 1 & 1 & 1 & 1 & 4 & $\mathbf{0}$ \\
\hline 8 & 1 & 1 & 1 & 1 & 4 & $\mathbf{0}$ \\
\hline 10 & 1 & 1 & 1 & 1 & 4 & $\mathbf{0}$ \\
\hline 15 & 1 & 1 & 1 & 1 & 4 & $\mathbf{0}$ \\
\hline 21 & 1 & 1 & 1 & 1 & 4 & $\mathbf{0}$ \\
\hline 22 & 1 & 1 & 1 & 1 & 4 & $\mathbf{0}$ \\
\hline 24 & 1 & 1 & 1 & 1 & 4 & $\mathbf{0}$ \\
\hline
\end{tabular}


Table 16: Test 3: Implicational scaling of four cue types (cont.)

\begin{tabular}{|c|c|c|c|c|c|c|}
\hline \multicolumn{7}{|c|}{$100 \%$} \\
\hline 31 & 7 & 1 & 1 & 1 & 4 & $\overline{0}$ \\
\hline 32 & 1 & 1 & 1 & 1 & 4 & 0 \\
\hline 34 & 7 & 1 & 1 & 1 & 4 & $\overline{0}$ \\
\hline 35 & 7 & 1 & 1 & 1 & 4 & $\overline{0}$ \\
\hline 37 & 7 & 1 & $\overline{1}$ & 1 & 4 & 0 \\
\hline 45 & 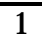 & 1 & 1 & 1 & 4 & $\overline{0}$ \\
\hline 47 & 7 & 1 & 1 & 1 & 4 & $\overline{0}$ \\
\hline 54 & 7 & 1 & $\overline{1}$ & 1 & 4 & 0 \\
\hline 55 & 1 & 1 & 1 & 1 & 4 & $\overline{0}$ \\
\hline 57 & 1 & 1 & 1 & 1 & 4 & $\overline{0}$ \\
\hline 2 & 7 & 1 & $\overline{1}$ & $\overline{0}$ & 3 & 0 \\
\hline 3 & 1 & 1 & 1 & $\overline{0}$ & 3 & $\overline{0}$ \\
\hline 6 & 1 & 1 & 1 & $\overline{0}$ & 3 & $\overline{0}$ \\
\hline 14 & 1 & 1 & 1 & $\overline{0}$ & 3 & 0 \\
\hline 17 & 1 & 1 & 1 & $\overline{0}$ & 3 & $\overline{0}$ \\
\hline 19 & 1 & 1 & 1 & $\overline{0}$ & 3 & $\overline{0}$ \\
\hline 25 & 1 & 1 & 1 & $\overline{0}$ & 3 & 0 \\
\hline 27 & 1 & 1 & 1 & $\overline{0}$ & 3 & $\overline{0}$ \\
\hline 29 & 1 & 1 & 1 & $\overline{0}$ & 3 & $\overline{0}$ \\
\hline 30 & 1 & 1 & 1 & $\overline{0}$ & 3 & 0 \\
\hline 39 & 1 & 1 & 1 & $\overline{0}$ & 3 & $\overline{0}$ \\
\hline 40 & 1 & 1 & 1 & $\overline{0}$ & 3 & $\overline{0}$ \\
\hline 41 & 1 & 1 & 1 & $\overline{0}$ & 3 & $\overline{0}$ \\
\hline 42 & 1 & 1 & 1 & $\overline{0}$ & 3 & $\overline{0}$ \\
\hline 46 & 1 & 1 & 1 & $\overline{0}$ & 3 & $\overline{0}$ \\
\hline 50 & 1 & 1 & 1 & $\overline{0}$ & 3 & $\overline{0}$ \\
\hline 52 & 1 & 1 & 1 & $\overline{0}$ & 3 & $\overline{0}$ \\
\hline 53 & 1 & 1 & 1 & $\overline{0}$ & 3 & $\overline{0}$ \\
\hline 58 & 1 & 1 & 1 & $\overline{0}$ & 3 & $\overline{0}$ \\
\hline 61 & 1 & 1 & 1 & 0 & 3 & $\overline{0}$ \\
\hline 62 & 1 & 1 & 1 & 0 & 3 & $\overline{0}$ \\
\hline 64 & 1 & 1 & 1 & $\overline{0}$ & 3 & 0 \\
\hline 4 & 1 & 1 & $\begin{array}{l}(0) \\
\end{array}$ & - & 3 & 2 \\
\hline 7 & 1 & 1 & $\begin{array}{l}(0) \\
\end{array}$ & - & 3 & 2 \\
\hline 9 & 1 & 1 & (0) & - & 3 & 2 \\
\hline 12 & 1 & 1 & (0) & - & 3 & 2 \\
\hline 13 & 1 & 1 & (0) & - & 3 & 2 \\
\hline 20 & 1 & 1 & (0) & - & 3 & 2 \\
\hline 28 & 1 & 1 & (0) & - & 3 & 2 \\
\hline 36 & 1 & 1 & (0) & - & 3 & 2 \\
\hline 38 & 1 & 1 & $(0)$ & - & 3 & 2 \\
\hline 44 & 1 & 1 & (0) & - & 3 & 2 \\
\hline 59 & 1 & 1 & (0) & - & 3 & 2 \\
\hline 16 & 1 & 1 & 0 & 0 & 2 & 0 \\
\hline 23 & 1 & 1 & 0 & 0 & 2 & 0 \\
\hline 43 & 1 & 1 & 0 & $\overline{0}$ & 2 & 0 \\
\hline 49 & 1 & 1 & 0 & 0 & 2 & 0 \\
\hline 11 & 1 & (0) & 0 & - & 2 & 2 \\
\hline 33 & 1 & (0) & 0 & - & 2 & 2 \\
\hline 56 & 1 & (0) & 0 & - & 2 & 2 \\
\hline
\end{tabular}


Table 16 (cont.): Test 3: Implicational scaling of four cue types

\begin{tabular}{|c|c|c|c|c|c|c|}
\hline 5 & 1 & 0 & 0 & 0 & 1 & 0 \\
\hline 18 & 1 & 0 & 0 & 0 & 1 & 0 \\
\hline 26 & 1 & 0 & 0 & 0 & 1 & 0 \\
\hline 48 & 1 & 0 & 0 & 0 & 1 & 0 \\
\hline 51 & 1 & 0 & 0 & 0 & 1 & 0 \\
\hline 63 & 1 & 0 & 0 & 0 & 1 & 0 \\
\hline 60 & 0 & 0 & 0 & 0 & 0 & 0 \\
\hline sum & 63 & 54 & 39 & 31 & 187 & 28 \\
\hline$p$ & .98 & .84 & .61 & .48 & & \\
\hline$q$ & .02 & .16 & .39 & .52 & & \\
\hline CR & .89 & & & & & \\
\hline MMR & .73 & & & & & \\
\hline PI & .16 & & & & & \\
\hline $\mathrm{CS}$ & .59 & & & & & \\
\hline
\end{tabular}

Table 17: Test 3: Implicational scaling of three cue types

\begin{tabular}{|c|c|c|c|c|c|c|c|c|c|c|c|}
\hline \multicolumn{12}{|c|}{$100 \%$} \\
\hline ID & $\begin{array}{c}\text { MMM/ } \\
\text { FFF }\end{array}$ & $\begin{array}{c}\text { МMØ/ } \\
\text { FFØ }\end{array}$ & MMF & sum & error & ID & $\begin{array}{c}\text { MMM/ } \\
\text { FFF }\end{array}$ & $\begin{array}{c}\text { MMØ/ } \\
\text { FFØ }\end{array}$ & $\begin{array}{c}\text { MFM/ } \\
\text { FMF }\end{array}$ & sum & error \\
\hline 1 & 1 & 1 & 1 & 3 & 0 & 1 & 1 & 1 & 1 & 3 & 0 \\
\hline 2 & 1 & 1 & 1 & 3 & 0 & 4 & 1 & 1 & 1 & 3 & 0 \\
\hline 3 & 1 & 1 & 1 & 3 & 0 & 7 & 1 & 1 & 1 & 3 & 0 \\
\hline 6 & 1 & 1 & 1 & 3 & 0 & 8 & 1 & 1 & 1 & 3 & 0 \\
\hline 8 & 1 & 1 & 1 & 3 & 0 & 9 & 1 & 1 & 1 & 3 & 0 \\
\hline 10 & 1 & 1 & 1 & 3 & 0 & 10 & 1 & 1 & 1 & 3 & 0 \\
\hline 14 & 1 & 1 & 1 & 3 & 0 & 12 & 1 & 1 & 1 & 3 & 0 \\
\hline 15 & 1 & 1 & 1 & 3 & 0 & 13 & 1 & 1 & 1 & 3 & 0 \\
\hline 17 & 1 & 1 & 1 & 3 & 0 & 15 & 1 & 1 & 1 & 3 & 0 \\
\hline 19 & 1 & 1 & 1 & 3 & 0 & 20 & 1 & 1 & 1 & 3 & 0 \\
\hline 21 & 1 & 1 & 1 & 3 & 0 & 21 & 1 & 1 & 1 & 3 & 0 \\
\hline 22 & 1 & 1 & 1 & 3 & 0 & 22 & 1 & 1 & 1 & 3 & 0 \\
\hline 24 & 1 & 1 & 1 & 3 & 0 & 24 & 1 & 1 & 1 & 3 & 0 \\
\hline 25 & 1 & 1 & 1 & 3 & 0 & 28 & 1 & 1 & 1 & 3 & 0 \\
\hline 27 & 1 & 1 & 1 & 3 & 0 & 31 & 1 & 1 & 1 & 3 & 0 \\
\hline 29 & 1 & 1 & 1 & 3 & 0 & 32 & 1 & 1 & 1 & 3 & 0 \\
\hline 30 & 1 & 1 & 1 & 3 & 0 & 34 & 1 & 1 & 1 & 3 & 0 \\
\hline 31 & 1 & 1 & 1 & 3 & 0 & 35 & 1 & 1 & 1 & 3 & 0 \\
\hline 32 & 1 & 1 & 1 & 3 & 0 & 36 & 1 & 1 & 1 & 3 & 0 \\
\hline 34 & 1 & 1 & 1 & 3 & 0 & 37 & 1 & 1 & 1 & 3 & 0 \\
\hline 35 & 1 & 1 & 1 & 3 & 0 & 38 & 1 & 1 & 1 & 3 & 0 \\
\hline 37 & 1 & 1 & 1 & 3 & 0 & 44 & 1 & 1 & 1 & 3 & 0 \\
\hline 39 & 1 & 1 & 1 & 3 & 0 & 45 & 1 & 1 & 1 & 3 & 0 \\
\hline 40 & 1 & 1 & 1 & 3 & 0 & 47 & 1 & 1 & 1 & 3 & 0 \\
\hline 41 & 1 & 1 & 1 & 3 & 0 & 54 & 1 & 1 & 1 & 3 & 0 \\
\hline 42 & 1 & 1 & 1 & 3 & 0 & 55 & 1 & 1 & 1 & 3 & 0 \\
\hline 45 & 1 & 1 & 1 & 3 & 0 & 57 & 1 & 1 & 1 & 3 & 0 \\
\hline 46 & 1 & 1 & 1 & 3 & 0 & 59 & 1 & 1 & 1 & 3 & 0 \\
\hline 47 & 1 & 1 & 1 & 3 & 0 & 2 & 1 & 1 & 0 & 2 & 0 \\
\hline 50 & 1 & 1 & 1 & 3 & 0 & 3 & 1 & 1 & 0 & 2 & 0 \\
\hline 52 & 1 & 1 & 1 & 3 & 0 & 6 & 1 & 1 & 0 & 2 & 0 \\
\hline 53 & 1 & 1 & 1 & 3 & 0 & 14 & 1 & 1 & 0 & 2 & 0 \\
\hline 54 & 1 & 1 & 1 & 3 & 0 & 16 & 1 & 1 & 0 & 2 & 0 \\
\hline 55 & 1 & 1 & 1 & 3 & 0 & 17 & 1 & 1 & 0 & 2 & 0 \\
\hline
\end{tabular}


Table 17 (cont.): Test 3: Implicational scaling of three cue types

\begin{tabular}{|c|c|c|c|c|c|c|c|c|c|c|c|}
\hline 57 & 1 & 1 & 1 & 3 & 0 & 19 & 1 & 1 & 0 & 2 & 0 \\
\hline 58 & 1 & 1 & 1 & 3 & 0 & 23 & 1 & 1 & 0 & 2 & 0 \\
\hline 61 & 1 & 1 & 1 & 3 & 0 & 25 & 1 & 1 & 0 & 2 & 0 \\
\hline 62 & 1 & 1 & 1 & 3 & 0 & 27 & 1 & 1 & 0 & 2 & 0 \\
\hline 64 & 1 & 1 & 1 & 3 & 0 & 29 & 1 & 1 & 0 & 2 & 0 \\
\hline 4 & 1 & 1 & 0 & 2 & 0 & 30 & 1 & 1 & 0 & 2 & 0 \\
\hline 7 & 1 & 1 & 0 & 2 & 0 & 39 & 1 & 1 & 0 & 2 & 0 \\
\hline 9 & 1 & 1 & 0 & 2 & 0 & 40 & 1 & 1 & 0 & 2 & 0 \\
\hline 12 & 1 & 1 & 0 & 2 & 0 & 41 & 1 & 1 & 0 & 2 & 0 \\
\hline 13 & 1 & 1 & 0 & 2 & 0 & 42 & 1 & 1 & 0 & 2 & 0 \\
\hline 16 & 1 & 1 & 0 & 2 & 0 & 43 & 1 & 1 & 0 & 2 & 0 \\
\hline 20 & 1 & 1 & 0 & 2 & 0 & 46 & 1 & 1 & 0 & 2 & 0 \\
\hline 23 & 1 & 1 & 0 & 2 & 0 & 49 & 1 & 1 & 0 & 2 & 0 \\
\hline 28 & 1 & 1 & 0 & 2 & 0 & 50 & 1 & 1 & 0 & 2 & 0 \\
\hline 36 & 1 & 1 & 0 & 2 & 0 & 52 & 1 & 1 & 0 & 2 & 0 \\
\hline 38 & 1 & 1 & 0 & 2 & 0 & 53 & 1 & 1 & 0 & 2 & 0 \\
\hline 43 & 1 & 1 & 0 & 2 & 0 & 58 & 1 & 1 & 0 & 2 & 0 \\
\hline 44 & 1 & 1 & 0 & 2 & 0 & 61 & 1 & 1 & 0 & 2 & 0 \\
\hline 49 & 1 & 1 & 0 & 2 & 0 & 62 & 1 & 1 & 0 & 2 & 0 \\
\hline 59 & 1 & 1 & 0 & 2 & 0 & 64 & 1 & 1 & 0 & 2 & $\overline{0}$ \\
\hline 5 & 1 & 0 & 0 & 1 & 0 & 11 & 1 & (0) & - & 2 & 2 \\
\hline 11 & 1 & 0 & 0 & 1 & 0 & 33 & 1 & (0) & - & 2 & 2 \\
\hline 18 & 1 & 0 & 0 & 1 & 0 & 56 & 1 & (0) & - & 2 & 2 \\
\hline 26 & 1 & 0 & 0 & 1 & 0 & 5 & 1 & 0 & 0 & 1 & 0 \\
\hline 33 & 1 & 0 & 0 & 1 & 0 & 18 & 1 & 0 & 0 & 1 & 0 \\
\hline 48 & 1 & 0 & 0 & 1 & 0 & 26 & 1 & 0 & 0 & 1 & 0 \\
\hline 51 & 1 & 0 & 0 & 1 & 0 & 48 & 1 & 0 & 0 & 1 & 0 \\
\hline 56 & 1 & 0 & 0 & 1 & 0 & 51 & 1 & 0 & 0 & 1 & 0 \\
\hline 63 & 1 & 0 & 0 & 1 & 0 & 63 & 1 & 0 & 0 & 1 & 0 \\
\hline 60 & 0 & 0 & 0 & 0 & 0 & 60 & 0 & 0 & 0 & 0 & 0 \\
\hline sum & 63 & 54 & 39 & 156 & 0 & sum & 63 & 54 & 31 & 148 & 6 \\
\hline$p$ & .98 & .84 & .61 & & & $p$ & .98 & .84 & .48 & & \\
\hline$q$ & .02 & .16 & .39 & & & $q$ & .02 & .16 & .52 & & \\
\hline CR & 1.00 & & & & & CR & .97 & & & & \\
\hline MMR & .81 & & & & & MMR & .77 & & & & \\
\hline PI & .19 & & & & & PI & .20 & & & & \\
\hline CS & 1.00 & & & & & CS & .86 & & & & \\
\hline
\end{tabular}

\section{Discussion}

Table 4 shows that the participants were acutely attuned to the gender clues inherent in the - $O$ and $-a$ endings as predicted. Also as hypothesized, the students associated $-i$ more often with the masculine $(72 \%)$ and $-e$ with the feminine $(68 \%)$. Although they were told that all of the nouns were singular, it is likely that the strong gender associations with the masculine plural $-i$ and the feminine plural $-e$ endings influenced their choices. The results show that on the average they associated both consonant and $-u$ with the masculine at similar rates, $(80 \% / 82 \%$ respectively), which in the case of $-u$ was an incorrect strategy, as it is usually associated with the feminine. It is not clear whether the students assigned-consonant endings to the masculine because they knew this to be the general association. Given the similarity between the scores on -consonant and $-u$, both uncommon endings, it is possible that the students assigned nouns to the masculine when they were not certain of their gender. It is not clear why 
the noun smoking and elettrolisi elicited a higher number of masculine responses than the other members of their -consonant and $-i$ categories.

It is evident that students are sensitive to cues in the final phoneme, though it is not clear to what extent they have developed the ability to perform what Tucker, et al. (1977) have called "backward processing." This skill appeared negligible in cases in which there was conflict between a suffix and its final letter, e.g.,-cida. Only a very small number of students were able to recognize the suffix -ista and the syllable - $m a$ as cues to masculine gender. The latter is actually the most reliable of the three cue types, since-ista and -cida are feminine when they refer to women. It is possible that those responding correctly to - $m a$ items arrived at their choice through analogy with the common il problema (the problem), probably the most salient member of the category. Taking into consideration the limited frequency of such endings compared to the ubiquitous feminine $-a$, the poor performance of the large majority of students is not surprising. In the case of a final letter which gives no clue to gender in the singular, i.e., $-e$, they may process backwards for clues, a possibility suggested by the students' ability, albeit limited, to distinguish between the gender associations of -trice and -tore (see Table 8). It is possible that the higher scores on these two suffixes relate to their saliency as markers of natural gender. Given that this subtest was made up of only two items of each category, the results are only suggestive and require further investigation.

The results of Test 2 (see Table 10) show that when the definite article is added to a noun with clear gender marking, e.g., $-o$ or $-a$, the results are similar to those in Test 1 where the noun was given alone. When the syntactic cue is the only one given, the performance decreased only slightly (from 99.2 to $96.1 \%$ ), suggesting that although it may be easier to process gender when cues on both the noun and article are available, the students, in most cases, are able to choose the correct gender from cues on the article alone. When there was an ambiguous syntactic cue with a clear morphophonological cue, the accuracy level was surprisingly low (70\%), considering the perfect and near perfect scores on nouns ending in $-o$ and $-a$ in Test 1 . The reason for the difficulty appears to lie in the unfortunate choice of two of the four examples of this category. Both items, l'emolumento and l'ossatura, have initial sounds which can be confused with articles that are clearly marked for gender, conflicting in each case with the marking on the noun, i.e., le (feminine) and lo (masculine). The accuracy rates for these two items are nearly equal (52\%/53\% respectively, compared to scores of $86 \%$ and $91 \%$ for the other two items in this category), suggesting that the students were influenced by the perceived syntactic cues in the beginnings of the nouns. When the two ambiguous test items were removed, the average score for the category of no syntactic cue + morphophonological cue rose to $88.3 \%$, yet it is still lower than that for the category of syntactic cue + no morphophonological cue $(96.1 \%)$. The fact that the score for items in the category no syntactic cue + morphophonological cue is lower than those for items ending in $-o$ and $-a$ on Test 1 suggests some uncertainty resulting from an attempt to identify the article in each case. It appears that even the presence of an article without gender marking, made focusing on the cue in the noun ending slightly more difficult than when the noun was presented alone. The score for the items with conflicting gender cues $(88.3 \%)$ demonstrates that discord is more problematic than accord, though the students are generally able to focus on the more reliable syntactic cues. From the mean scores, it seems that the group, on the whole, used a syntactic strategy, but was aided by a complementary cue on the noun and was also able to use that cue when the article was not marked for gender .

An examination of the implicational scale (see Table 12) gives evidence that there were important differences among the participants. It appears that the students can be divided into three main groups based on the different strategies they used. The largest group was able to take account of cues in the article or noun alone, but used a syntactic strategy when there was conflict between the syntactic and morphophonological cues. A second, smaller, group also appeared to use a syntactic strategy, to the 
extent that they were unable to assign gender to nouns that lacked gender marking on their article. A third group, on the other hand, appeared to follow a morphophonological strategy: they did well when the morphonological cue was alone or in accord with the syntactic cue, but their results were inconsistent when the cue on the noun ending was missing or was in discord with the cue on the article. There was also a very small group of students who were able to assign gender when there was a morphophonological cue but not when there was a syntactic cue alone. The implicational scales are somewhat misleading, though, in that two items have been removed from the 1 cue - morphophonological category, thus making it easier for students to get a point for $100 \%$ correctness for that category than for the others which had four items, also true for the two-item no cues category. It can be assumed that the figures for 1 cue-morphophonological would have been lower if there had been four items and thus also the number of students who appeared to use a morphophonological strategy.

In Test 3 (see Table 14), students did extremely well when there were three complementary cues, with a slight drop in accuracy, similar to that in Test 2 (see Table 10) when one cue was removed. As in Test 2, discord among cues was more problematic than accord. When the morphophonological cue conflicted with the syntactic and semantic cues the scores dropped markedly, indicating the use of a morphophonological strategy. An even greater decrease in accuracy was exhibited when the natural gender of the referent was in discord with the gender marking on the noun and article. As predicted, natural gender proved to be a strong cue for a large number of students. As Test 3 was a written exam, allowing the students greater opportunities to reflect on their choices, it can be expected that scores would have been even lower had the exam been presented in oral form only.

Once again, the implicational scales provide a better understanding of the differences among the participants. The scales give evidence of the existence of several groups using differing strategies in Test 3 as well. Here, too, one group coped well with both complementary and conflicting cues, while a second had difficulty with those items in which the gender of the referent conflicted with the other two cues. It is possible that this group used a semantic strategy throughout, given that in all of the other categories choosing the natural gender provided the correct answer. A third group had difficulty only when the morphophonological cue conflicted with the other cues, suggesting a morphophonological strategy, though they were able to cope with a combination of semantic/syntactic cues where marking on the noun was not available (except for a small number of students). Another small group had difficulty with both types of conflicting cues, and still another needed three complementary cues in order to perform without errors.

The overall results for these tests do not confirm the masculine as the unmarked gender, as they show that in every case, it was chosen at a lower rate than it actually appeared on the tests. Students performed better with feminine nouns on each test as well, also suggesting that the masculine is not the unmarked form. On Test 1, this may have been the result of the presence of masculine nouns with derivational suffixes ending in $-a$, while there were no examples of feminine suffixes ending in -0 , as they do not exist. The students' tendency to assign masculine gender to nouns ending in $-u$ and -consonant suggest that perhaps the masculine was chosen when the endings provided no clear gender marking. This question requires further investigation.

The results of this study give evidence that gender assignment is least problematic when there are complementary cues, while the existence of conflicting cues creates a certain amount of confusion. ${ }^{2}$

2 The large number of crossed out answers for items with cues in discord gives anecdotal support to the statistical evidence of this phenomenon. This was particularly noticeable when the semantic cue was in conflict with the syntactic and morphophonological cues. 
This fact suggests that the students were simultaneously processing a number of cues, though their ability to cope with them successfully varied, according to the type of strategy they were following.

While in several other studies, choosing the semantic cue over the morphophonological cue was considered a mature strategy (Cain, et al., 1987; Karmiloff-Smith, 1979; Marinova-Todd, 1994 (as cited in Bialystok, 1997); Pérez-Pereira, 1991; Stevens, 1984), in this study many of the participants focused on the semantic cue even when it conflicted with the gender of the article. Though a semantic strategy is usually not detrimental in Italian, given that grammatical gender largely follows natural gender, there are enough exceptions to create difficulties. The underlying problem lies in the students' lack of awareness of the greater importance of cues in the syntactic agreement.

This study has suggested tendencies of certain English speakers learning grammatical gender in Italian. Still much more research is needed in order to better understand the complex phenomenon of acquisition of grammatical gender. In order to expand on the results of this study, research is required which looks at a larger sample of cue types and has an equal number of items of every type. Are students within the same classroom truly following different strategies regarding grammatical gender? If so, how does the choice of strategy relate to L1 background, sex, and level of study? This study did not take into consideration demographic information on the participants, though it could have yielded important insights. How does cue sensitivity relate to spontaneous production, both spoken and written?

While the results of this study are tentative and require follow-up, they do suggest some implications for teaching. First of all, they point to the fact that, since students appear able to focus on cues in noun endings, it seems worthwhile to draw their attention to consistent patterns in endings beyond $-o$ and $-a$. This would be particularly worthwhile in the case of the suffixes which reliably predict gender. The ability to focus on the gender cue in a suffix, in many cases, can disambiguate the gender of a noun ending in -e. Once students have developed a good understanding of the common gender associations of many endings, the teacher may want to focus their attention on cases of discord among the cue types, in which actual gender assignment conflicts with the students' expectancies. Practice with these exceptions to the general patterns would be helpful for students who are following problematic strategies. Encouraging the students to notice agreement cues that demonstrate the gender of a noun ending in $-e$ could also foster greater understanding of the essential role of syntactic cues.

From the research on language acquisition in French immersion programs (Harley, 1979, in press; Stevens, 1984), it appears that, while important, providing numerous opportunities to listen to and speak a foreign language is not enough to ensure the acquisition of grammatical gender; active intervention seems required. Rather than resorting to teaching prescriptive gender "rules," the challenge, according to Harley (in press), is to draw students' attention to patterns and then to engage them in interesting tasks whose completion requires making accurate gender distinctions. 


\section{References}

Andersen, R. W. (1976). An implicational model for second language research. Language Learning, 28, 221-282.

Andersen, R. W. (1984). What's gender good for anyway? In R. Andersen (Ed.), Second languages: A crosslinguistic perspective (pp. 77-100). Rowley, MA: Newbury House.

Berman, R. (1986). Acquisition of Hebrew. In D. I. Slobin (Ed.), The crosslinguistic study of language acquisition (Vol. 1, pp. 255-372). Hillsdale, NJ: Lawrence Erlbaum.

Bialystok, E. (1997). The structure of age: In search of barriers to second language acquisition. Second Language Research., 13, 116-137.

Brown, J. D. (1983). An exploration of morpheme-group interactions. In K. M. Bailey, M. Long, and S. Peck (Eds.), Second language acquisition studies, pp. 25-40. Rowley, MA: Newbury House.

Cain, J., Weber-Olsen, M., \& Smith, R. (1987). Acquisition strategies in a first and second language: Are they the same? Journal of Child Language, 14, 333-352.

Carroll, S. (1989). Second-language acquisition and the computational paradigm. Language Learning, 39 , 535-594.

Clark, E. V. (1986). Acquisition of Romance, with special reference to French. In D. I. Slobin (Ed.), The crosslinguistic study of language acquisition (Vol. 1, pp. 687-782). Hillsdale, NJ: Lawrence Erlbaum.

Dardano, M., \& Trifone, M. (1989). Grammatica italiana (2nd ed.). Bologna (Italy): Zanichelli.

Delisle, H. H. (1985). The acquisition of gender by American students of German. The Modern Language Journal, 69, 55-63.

Desrochers, A., Gélinas, C., and Wieland, L.D. (1989). An application of the mnemonic keyword method to the acquisition of German nouns and their grammatical gender. Journal of Educational Psychology, 81, 25-32.

Finneman, M.D., (1992). Learning agreement in the noun phrase: The strategies of three first-year Spanish students. IRAL, 30, 121-136

Hardison, D. M. (1992). Acquisition of grammatical gender in French: L2 learner accuracy and strategies. The Canadian Modern Language Review, 48, 292-306.

Harley, B. (1979). French gender 'rules' in the speech of English-dominant, French-dominant and monolingual French-speaking children. Working Papers in Bilingualism, 19, 129-156.

Harley, B. (in press). The role of form-focused tasks in promoting the second language acquisition of children in Grade 2. In C. Doughty \& J. Williams (Eds.), Focus on form in classroom second language acquisition. Cambridge: Cambridge University Press.

Hatch, E., \& Lazaraton, A. (1991). The research manual: Design and statistics for applied linguistics. Boston: Heinle \& Heinle.

Karmiloff-Smith, A. (1979). A functional approach to child language. Cambridge: Cambridge University Press.

Koehn, C. (1994). The acquisition of gender and number morphology within NP. In J. M. Meisel (Ed.), Bilingual first language acquisition: French and German grammar development (pp. 29-51).

Amsterdam: Benjamins. 
Levy, Y. (1983). The acquisition of Hebrew plurals: The case of the missing gender category. Journal of Child Language, 10, 107-121.

Levy, Y. (1988). On the early learning of formal grammatical systems: Evidence from studies of the acquisition of gender and acountability. Journal of Child Language, 15, 179-187.

Luce, S. L. (1979). Learning French genders with "e's". French Review, 52, 567-574.

Magnan, S. (1983). Age and sensitivity to gender. Studies in Second Language Acquisition, 5, 194-212.

Mills, A. E. (1986). The acquisition of gender: A study of English and German. Berlin: Springer-Verlag.

Müller, N. (1994). Gender and number agreement within DP. In J. M. Meisel (Ed.), Bilingual first language acquisition: French and German grammar development (pp. 53-88). Amsterdam: Benjamins.

Nie, N. H., Jull, H., Steinbrenner, K. \& Bent, D. (1975). Statistical package for the social sciences (2 ${ }^{\text {nd }}$ ed.). New York:McGraw-Hill.

Pérez-Pereira, M. (1991). The acquisition of gender: What Spanish children tell us. Journal of Child Language, 18, 571-590.

Rogers, M. (1987). Learners' difficulties with grammatical gender in German as a foreign language. Applied Linguistics, 8, 48-74.

Stevens, F. (1984). Strategies for second language acquisition. Montreal: Eden Press.

Surridge, M. E. (1993). Gender assignment in French: The hierarchy of rules and the chronology of acquisition. IRAL, 31 (2), 77-95.

Surridge, M. E., \& Lessard, G. (1984). Pour une prise de conscience du genre grammatical. The Canadian Modern Language Review, 41, 43-52.

Tucker, G. R., Lambert, W. E., \& Rigault A. (1969). Students' acquisition of French gender distinctions: A pilot investigation. IRAL, 3, 51-55.

Tucker, G. R., Lambert, W. E., \& Rigault A. A. (1977). The French speaker's skill with grammatical gender: An example of rule-governed behavior. The Hague: Mouton.

Zekhnini, A., \& Hulstijn, J. H. (1995). An experimental study on the learning of arbitrary and nonarbitrary gender of pseudo Dutch nouns by nonnative and native speakers of Dutch. Applied Linguistics in Articles, 53, 121-136. 


\section{Appendix A Test 1: Breakdown by category}

\begin{tabular}{|c|c|c|}
\hline ending & test item & \% correct \\
\hline$-O$ & $\begin{array}{l}\text { batacchio }(\mathrm{m}) \\
\text { frasario }(\mathrm{m}) \\
\text { pelago }(\mathrm{m}) \\
\text { portello }(\mathrm{m}) \\
\end{array}$ & $\begin{array}{r}98 \\
100 \\
100 \\
100\end{array}$ \\
\hline$-a$ & $\begin{array}{c}\text { cova }(\mathrm{f}) \\
\text { fistola }(\mathrm{f}) \\
\text { grinza (f) } \\
\text { tenia (f) }\end{array}$ & $\begin{array}{r}100 \\
95 \\
100 \\
95\end{array}$ \\
\hline -consonant & $\begin{array}{l}\text { duplex }(\mathrm{m}) \\
\text { hinterland }(\mathrm{m}) \\
\text { nylon }(\mathrm{m}) \\
\text { smoking }(\mathrm{m})\end{array}$ & $\begin{array}{l}75 \\
80 \\
77 \\
97\end{array}$ \\
\hline$-e$ & $\begin{array}{c}\text { fortunale }(\mathrm{m}) \\
\text { lendine }(\mathrm{m}) \\
\text { selce }(\mathrm{f}) \\
\operatorname{varice}(\mathrm{f})\end{array}$ & $\begin{array}{l}30 \\
34 \\
66 \\
69\end{array}$ \\
\hline$-i$ & $\begin{array}{l}\text { eclissi (f) } \\
\text { elettrolisi (f) } \\
\text { genesi (f) } \\
\text { sintesi (f) }\end{array}$ & $\begin{array}{l}30 \\
19 \\
34 \\
30\end{array}$ \\
\hline$-u$ & $\begin{array}{l}\text { gioventù (f) } \\
\text { gru (f) } \\
\text { schiavitù (f) } \\
\text { servitù (f) }\end{array}$ & $\begin{array}{l}17 \\
22 \\
17 \\
23\end{array}$ \\
\hline -trice & $\begin{array}{l}\text { fattrice }(\mathrm{f}) \\
\text { levatrice }(\mathrm{f})\end{array}$ & $\begin{array}{l}69 \\
80\end{array}$ \\
\hline -tore & $\begin{array}{l}\text { liberatore }(\mathrm{m}) \\
\text { tornitore }(\mathrm{m})\end{array}$ & $\begin{array}{l}59 \\
67\end{array}$ \\
\hline $\begin{array}{r}\text {-sionel } \\
\text { zione }\end{array}$ & $\begin{array}{l}\text { dissipazione }(\mathrm{f}) \\
\text { immissione }(\mathrm{f})\end{array}$ & $\begin{array}{l}64 \\
58 \\
\end{array}$ \\
\hline -one & $\begin{array}{c}\text { festone }(\mathrm{m}) \\
\text { mollettone }(\mathrm{m})\end{array}$ & $\begin{array}{l}27 \\
59\end{array}$ \\
\hline$-m a$ & $\begin{array}{c}\text { stratagemma }(\mathrm{m}) \\
\text { teorema }(\mathrm{m})\end{array}$ & $\begin{array}{l}13 \\
14\end{array}$ \\
\hline -ista & $\begin{array}{c}\text { camionista }(\mathrm{m}) \\
\text { paracadutista }(\mathrm{m})\end{array}$ & $\begin{array}{r}10 \\
8 \\
\end{array}$ \\
\hline$-c i d a$ & $\begin{array}{l}\text { battericida }(\mathrm{m}) \\
\text { regicida }(\mathrm{m})\end{array}$ & $\begin{array}{l}2 \\
2\end{array}$ \\
\hline
\end{tabular}




\section{Appendix B Test 2: List of Items by Cue Type}

The first position indicates the syntactic cue on the article, while the second position indicates the morphophonological cue on the noun ending.

\begin{tabular}{|c|c|c|c|}
\hline cue type & $\begin{array}{l}\text { gender } \\
\text { of cues }\end{array}$ & test item & $\begin{array}{c}\% \\
\text { correct }\end{array}$ \\
\hline 2 like cues & $\begin{array}{c}\text { MM } \\
\text { MM } \\
\text { FF } \\
\text { FF }\end{array}$ & $\begin{array}{l}\text { il guercio }(\mathrm{m}) \\
\text { il reietto }(\mathrm{m}) \\
\text { la stanga }(\mathrm{f}) \\
\text { la virata }(\mathrm{f})\end{array}$ & $\begin{array}{c}98 \\
98 \\
100 \\
100\end{array}$ \\
\hline 1 cue - syntactic & $\begin{array}{l}\text { MØ } \\
\text { MØ } \\
\text { FØ } \\
\text { FØ }\end{array}$ & $\begin{array}{l}\text { il fanale }(\mathrm{m}) \\
\text { il polline }(\mathrm{m}) \\
\text { la termite }(\mathrm{f}) \\
\text { la caligine }(\mathrm{f})\end{array}$ & $\begin{array}{l}95 \\
95 \\
95 \\
98\end{array}$ \\
\hline conflicting cues & $\begin{array}{l}\text { MF } \\
\text { MF } \\
\text { FM } \\
\text { FM }\end{array}$ & $\begin{array}{l}\text { il barracuda }(\mathrm{m}) \\
\text { il preborsa }(\mathrm{m}) \\
\text { la dinamo }(\mathrm{f}) \\
\text { la virago }(\mathrm{f})\end{array}$ & $\begin{array}{l}89 \\
84 \\
88 \\
91\end{array}$ \\
\hline 1 cue $-\mathrm{mp}$ & $\begin{array}{l}\varnothing \mathrm{M} \\
\varnothing \mathrm{M} \\
\varnothing \mathrm{F} \\
\varnothing \mathrm{M}\end{array}$ & $\begin{array}{c}\text { l'emolumento }(\mathrm{m}) \\
\text { l'inghippo }(\mathrm{m}) \\
\text { l'ossatura }(\mathrm{f}) \\
\text { l'uremia }(\mathrm{f})\end{array}$ & $\begin{array}{l}53 \\
86 \\
52 \\
91\end{array}$ \\
\hline no cues & $\begin{array}{l}\varnothing \varnothing \\
\varnothing \varnothing\end{array}$ & $\begin{array}{l}\text { l'inguine }(\mathrm{m}) \\
\text { l'uranite }(\mathrm{f})\end{array}$ & $\begin{array}{l}30 \\
44\end{array}$ \\
\hline
\end{tabular}

$\mathrm{M}=$ masculine

$\mathrm{F}=$ feminine

$\varnothing=$ no gender marking 


\section{Appendix C Test 3: List of Items by Cue Type}

The first position indicates the syntactic cue on the article, the second position indicates the semantic cue in the form of a person's name, and the third position indicates the morphophonological cue on the noun ending.

\begin{tabular}{|c|c|c|c|}
\hline cue type & $\begin{array}{l}\text { gender } \\
\text { of cues }\end{array}$ & test item & $\begin{array}{c}\% \\
\text { correct }\end{array}$ \\
\hline $\begin{array}{r}3 \text { like cues } \\
(\mathrm{syn}=\mathrm{sem}=\mathrm{mp})\end{array}$ & $\begin{array}{l}\text { MMM } \\
\text { MMM } \\
\text { MMM } \\
\text { FFF } \\
\text { FFF } \\
\text { FFF }\end{array}$ & $\begin{array}{l}\text { Domenico è un vetraio distratto/distratta. }(\mathrm{m}) \\
\text { Marco è un fabbro taciturno/taciturna. }(\mathrm{m}) \\
\text { Tommaso è un calligrafo antipatico/antipatica. (m) } \\
\text { Laura è una centralinista bravo/brava. (f) } \\
\text { Lisa è una dattilografa svelto/svelta. (f) } \\
\text { Patrizia è una mondina povero/povera. (f) }\end{array}$ & $\begin{array}{r}100 \\
98 \\
100 \\
100 \\
100 \\
100\end{array}$ \\
\hline $\begin{array}{r}2 \text { like cues } \\
(\mathrm{syn}=\mathrm{sem}, \mathrm{mp}=\varnothing)\end{array}$ & $\begin{array}{l}\text { MMØ } \\
\text { MMØ } \\
\text { MMØ } \\
\text { FFØ } \\
\text { FFØ } \\
\text { FFØ }\end{array}$ & $\begin{array}{l}\text { Filippo è un falegname magro/magra. }(\mathrm{m}) \\
\text { Sergio è un bracciante allegro/allegra. }(\mathrm{m}) \\
\text { Vincenzo è un orefice preciso/precisa. }(\mathrm{m}) \\
\text { Alessandra è una custode grasso/grassa. (f) } \\
\text { Angelica è una docente esperto/esperta. (f) } \\
\text { Sofia è una preside nuovo/nuova. (f) }\end{array}$ & $\begin{array}{l}94 \\
98 \\
97 \\
97 \\
95 \\
95\end{array}$ \\
\hline $\begin{array}{r}\text { Cue discord } \\
\text { (syn }=\text { sem } \neq m p)\end{array}$ & $\begin{array}{l}\text { MMF } \\
\text { MMF } \\
\text { MMF }\end{array}$ & $\begin{array}{l}\text { Alberto è un despota ricco/ricca. }(\mathrm{m}) \\
\text { Francesco è un acquafortista innovativo/innovativa. }(\mathrm{m}) \\
\text { Carlo è un podista stanco/stanca. }(\mathrm{m})\end{array}$ & $\begin{array}{l}83 \\
69 \\
77\end{array}$ \\
\hline $\begin{array}{r}\text { Cue discord } \\
(\text { syn }=m p \neq \text { sem })\end{array}$ & $\begin{array}{l}\text { MFM } \\
\text { MFM } \\
\text { MFM } \\
\text { FMF } \\
\text { FMF } \\
\text { FMF }\end{array}$ & $\begin{array}{l}\text { Marta è un soprano famoso/famosa. (m) } \\
\text { Rita è un architetto serio/seria. (m) } \\
\text { Tina è un diplomatico saggio/saggia. (m) } \\
\text { Antonio è una vedetta attento/attenta. (f) } \\
\text { Giorgio è una birba noioso/noiosa. (f) } \\
\text { Pietro è una recluta simpatico/simpatica. (f) }\end{array}$ & $\begin{array}{l}67 \\
67 \\
69 \\
61 \\
64 \\
64\end{array}$ \\
\hline
\end{tabular}

$\mathrm{M}=$ masculine

$\mathrm{F}=$ feminine

$\varnothing=$ no gender marking 